\title{
Dense fibrillar collagen-based hydrogels as functional osteoid-mimicking scaffolds
}

\section{Gabriele Griffanti \& Showan N. Nazhat}

To cite this article: Gabriele Griffanti \& Showan N. Nazhat (2020) Dense fibrillar collagenbased hydrogels as functional osteoid-mimicking scaffolds, International Materials Reviews, 65:8, 502-521, DOI: $10.1080 / 09506608.2020 .1735828$

To link to this article: https://doi.org/10.1080/09506608.2020.1735828

\section{Published online: 18 Mar 2020.}

Submit your article to this journal ๘

Џ Article views: 436

Q View related articles $\longleftarrow$

View Crossmark data 4

4

Citing articles: 8 View citing articles 


\title{
Dense fibrillar collagen-based hydrogels as functional osteoid-mimicking scaffolds
}

\author{
Gabriele Griffanti (D) and Showan N. Nazhat (D) \\ Department of Mining and Materials Engineering, McGill University, Montréal, Canada
}

\begin{abstract}
There is an increasing need to generate novel materials for the treatment and augmentation of bone defects, affecting millions of people worldwide. Fibrillar type I collagen is the most abundant tissue matrix protein in bone, providing its key native scaffolding material. However, while in vitro reconstituted collagen hydrogels of physically entangled, nano-fibred meshes, have long served as three-dimensional cultures, their highly-hydrated nature impacts their physiological relevance. In an effort to create biomimetic collagen gels, approaches have been undertaken to generate osteoid-like environments with increased collagen concentrations, controlled fibrillar orientation, defined micro-architectures, and tailored mechanical properties. This review describes the state-of-the-art on collagen densification techniques, exploring their advantages, limitations and future perspectives for applications as bone grafts. Ultimately, by successfully mimicking the organic milieu of bone through acellular or cell-mediated mineralisation of the designed osteoid-like structure, functional collagen scaffolds with potential applications in bone tissue engineering can be realised.
\end{abstract}

Abbreviations: 3D: three-dimensional; BG: bioactive glass; CFD: collagen fibrillar density; CHA: carbonated-hydroxyapatite; Col1: Type I collagen; ECM: extracellular matrix; GAE: gel aspirationejection; HHC: highly hydrated collagen; MSC: mesenchymal stem cell; NCPs: non-collagenous proteins; PC: plastic compression; PILP: polymer-induced liquid precursor; SBF: simulated body fluid
ARTICLE HISTORY

Received 14 October 2018

Accepted 24 February 2020

\section{KEYWORDS}

Dense collagen hydrogels; mineralization; bone; tissue engineering; extracellular matrix; hydroxyapatite; bioprinting; $\mathrm{RAFT}^{\mathrm{TM}}$

\section{Introduction}

Worldwide, more than two million bone grafting procedures are performed annually to treat bone defects, which may arise from trauma, congenital disease, tissue/vascular necrosis or tumour radiotherapy/excision [1]. In developed countries, rising rates of obesity and the aging population are expected to dramatically increase the demand for orthopaedic procedures and associated waiting periods for patient treatment. Current bone repair techniques include a combination of autologous, allogeneic, and prosthetic materials. Although these approaches achieve a degree of functional restoration, they possess inherent limitations, such as donor-site morbidity, unpredictable graft resorption, insufficient autologous resources, viral disease transmission, immunologic incompatibility, and structural failure [1]. Bone tissue engineering, with its primary aim being the restoration of function through delivery of viable elements and integration into living tissues has, in the last three decades, emerged as a viable alternative method for bone repair $[1,2]$. Bone tissue engineering can involve seeding osteoblastic cells from a donor source onto a biocompatible, degradable scaffold in vitro and either implanting immediately or after a predefined culture period [2]. Therefore, the composition, three-dimensional (3D) assembly, and resulting meso-scale structure of the initial scaffold are critical. To this end, there is an ever-increasing demand for new biomaterials for the repair, replacement, construction or augmentation of bone.

It is well known that the structure of a tissue reflects its function [3], thus the recreation of the appropriate tissue micro-architecture should be a first objective in bone tissue engineering applications. The main element of the tissue micro-architecture is its extracellular matrix (ECM), which determines its mechanical properties and dictates the biological environment for cellular activity by direct or indirect actions [4]. Based on the relative amounts and organisation of the various ECM components, this molecular scaffold is unique to each tissue and reflects the distinct cellular functions within that tissue [4]. The ECM in bone is primarily made of type I collagen (Col1) and represents a preformed unmineralised matrix, called the osteoid, which serves as the native scaffolding material for bone formation [5]. Osteoblastic cells produce the collagenous matrix that self-assemble either in 
Table 1. Summary of the main approaches to design an osteoid and strategies for its acellular or cell-mediated mineralisation.

\begin{tabular}{|c|c|c|c|}
\hline \multicolumn{2}{|c|}{ Design of the osteoid } & \multirow{2}{*}{$\begin{array}{l}\text { Acellular mineralisation } \\
\text { Co-precipitation of calcium-phosphate based } \\
\text { solutions } \\
\text { Polymer-induced liquid-precursor }\end{array}$} & \multirow{2}{*}{$\begin{array}{c}\text { Cell-mediated mineralisation } \\
\text { Osteoid density-dependent osteoblast mediated }\end{array}$} \\
\hline Pre-fibrillogenesis & Reverse dialysis & & \\
\hline & Evaporation & $\begin{array}{l}\text { Co-precipitation of calcium-phosphate based } \\
\text { solutions }\end{array}$ & Non-reported \\
\hline & Injection & Non-reported & Non-reported \\
\hline & $\begin{array}{l}\text { Combined injection and reverse } \\
\text { dialysis }\end{array}$ & Simulated body fluid & Non-reported \\
\hline \multirow[t]{5}{*}{ Post-fibrillogenesis } & Plastic compression & Simulated body fluid & $\begin{array}{l}\text { Osteoid density-dependent pre-osteoblast } \\
\text { mediated }\end{array}$ \\
\hline & & Bioactive particle incorporation & $\begin{array}{l}\text { Bioactive molecule stimulating bone-like cell } \\
\text { mineralisation }\end{array}$ \\
\hline & Biaxial compression & Non-reported & Non-reported \\
\hline & Gel aspiration-ejection & Simulated body fluid & $\begin{array}{l}\text { Osteoid density-dependent pre-osteoblast } \\
\text { mediated }\end{array}$ \\
\hline & & Bioactive particle incorporation & $\begin{array}{l}\text { Bioactive molecule stimulating bone-like cell } \\
\text { mineralisation }\end{array}$ \\
\hline
\end{tabular}

the extra-cellular space, or inside intracellular vesicles followed by the secretion of a package of aligned fibrils [6]. Next, calcium phosphate ions are accumulated inside vesicles within the osteoblasts. At this point, the mineral is in an amorphous state and vesicles are secreted into the collagenous ECM. Once secreted, the amorphous mineral is reduced into nanosized particles, which infiltrate the gaps in the collagen fibril where they crystallise [6], a process known as intrafibrillar mineralisation. However, the minerals not only crystallise within, but also in between collagen fibrils, i.e. inducing inter-fibrillar mineralisation [5].

Since collagen is not only the most abundant protein in the human body, but also the main component of the ECM of connective tissues including bone, collagen-based scaffolds are of significant interest as tissue-mimicking constructs [7]. In particular, as the ECM of bone is rich in Coll, this type of collagen has been widely used as a scaffolding biomaterial in bone tissue engineering [8]. For example, Coll sponges, membranes and films have been used to promote bone regeneration, whereas drug releasing Coll micro- and nano-spheres have been shown to increase the mineralisation ratio of bone marrow stromal cells, in vitro [8]. Coll-rich native ECM-derived scaffolds can also be produced by decellularisation, which aims to remove all cells and cellular antigens while retaining the bioactive cues that reside in tissues [9].

Coll can also be processed as a hydrogel. Indeed, by their adjustment to physiological $\mathrm{pH}$ and temperature, acid solubilised collagen molecules create reconstituted collagen hydrogels through spontaneous fibrillar selfassembly [10]. Fibril formation (akin to fibrillogenesis, in vivo), occurs at a range of physiological $\mathrm{pH}$, ionic strength and temperature to form the native D-banded fibrils, in vitro [10]. Fibril growth is preceded by a lag phase, which involves the formation of intermediate subassemblies [11] that have been identified as the aggregation of a single collagen molecule into $4 \mathrm{D}$-staggered dimers and trimers [12]. Fibrillar growth then ensues by the lateral association of trimers, which results in the overlap zones, creating the trademark regular D-banded pattern of collagen [12].

Col1 hydrogels allow for cell seeding and can be used as a model to study cell-matrix interactions [8], by providing a $3 \mathrm{D}$ environment, thus promoting in vivo-like cellular activity, and are recognised as being distinct from that generated by $2 \mathrm{D}$ cultures. Given these features, collagen hydrogels are appealing as osteoid-mimicking scaffolds [13]. However, commercial acidic solutions of Coll have concentrations ranging from 2 to $10 \mathrm{mg} \mathrm{mL}^{-1}$ and typically result in highly hydrated hydrogels with collagen fibrillar density (CFD; the percentage ratio of the dry-to-wet weight of the gels [14]) values of $<1 \mathrm{wt} . \%$, which is a consequence of the casting conditions. Therefore, due to the looseness of the fibrillar network, in vitro reconstituted Coll hydrogels lack the hierarchical structural organisation and mechanical properties of the native osteoid, representing a limitation for bone tissue engineering applications [15].

To overcome these drawbacks, strategies have been considered to increase the mechanical properties and to preserve the fibrillar network of collagen hydrogels. Various approaches have been developed to generate osteoid-like dense collagen matrices, which may be through increasing the initial collagen monomer concentration pre-fibrillogenesis [16], or increasing the gel CFD post-fibrillogenesis [14]. Once the desired osteoid-like structure has been designed, strategies to promote its mineralisation have been proposed (Table 1). The pre-fibrillogenesis approach consists of increasing the Coll solution concentration that is then neutralised to initiate the self-assembly and gelling process [16]. Research using this approach initially focused on geometries that can be obtained spontaneously in very condensed states [16], and that are similar to those observed in connective tissues [17]. Once the desired geometries were generated, the focus moved on to their acellular biomimetic mineralisation $[18,19]$, the structuring of bone apatite [20], and validation of the dense collagen osteoid models 

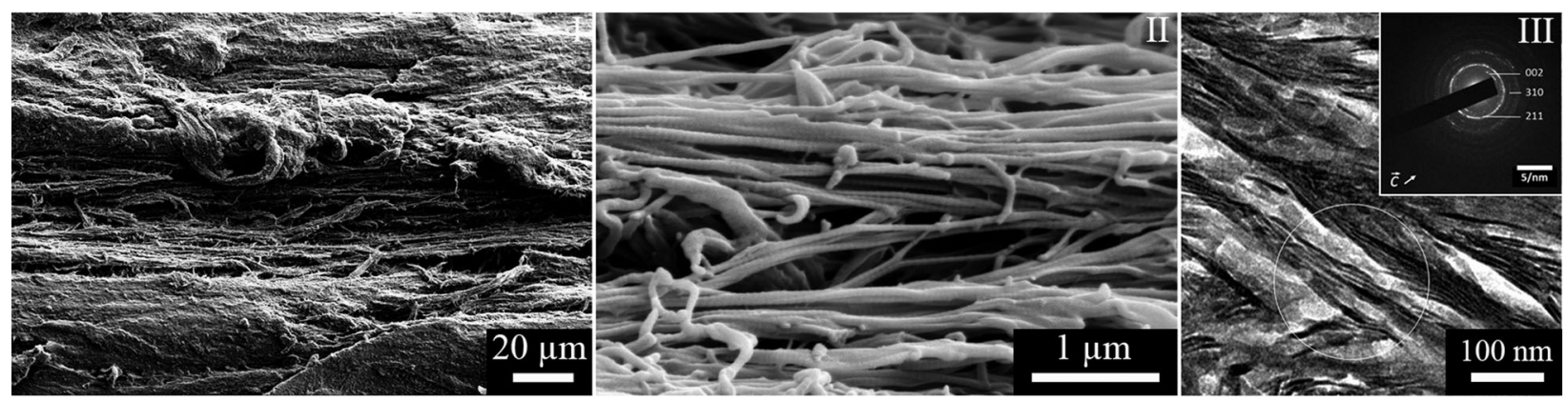

Figure 1. (I) Scanning electron microscopy (SEM) image of demineralised and critical point-dried fracture surface of human cortical lamellar bone. (II) Higher magnification SEM image of demineralised and critical point-dried human cortical lamellar bone presenting co-aligned collagen fibrils with the typical $67 \mathrm{~nm}$ D-banding pattern. I and II are kindly provided by Dr. Natalie Reznikov. (III) Transmission electron microscopy image of the filamentous pattern of mineralised collagen fibrils from human lamellar bone showing curved hydroxyapatite crystals of more than $100 \mathrm{~nm}$ in length. Inset, diffraction pattern from the circled area showing welldefined (002) plane-related reflections, which are oriented in the direction of the elongated crystals. Adapted from [6].

through in vitro and in vivo studies [21,22]. The postfibrillogenesis approaches of creating dense collagen gels rely on the expulsion of the casting fluid from already fibrilised precursor highly hydrated hydrogels, generated through the neutralisation of a low concentration (from $\sim 1-6 \mathrm{mg} \mathrm{mL}^{-1}$ ) Coll solutions $[14,23,24]$. Research on this approach has focused on the architectures $[14,23,24]$ and mechanical properties $[14,24,25]$ of gels of various CFDs. Along with acellular biomineralisation studies [26], bone cells or their precursors have been seeded in the osteoid-like matrix to validate the model [27-29], along with follow-up in vivo studies $[30,31]$.

This review discusses the various approaches that have been applied to generate and characterise dense collagen hydrogels as osteoid-mimicking models and their mineralisation. In particular, the investigations assessing hydrogel structural and mechanical properties, acellular and cellular approaches to reproduce the bone mineralisation process as well as some in vivo bone formation studies, are reviewed.

\section{Collagen}

Collagens can be found in multi-cellular animals, representing approximately $30 \%$ of all body proteins and constituting the most abundant form of naturally occurring scaffolds [32]. To date, twenty-nine collagen types have been identified as ECM macromolecules that contribute to both the mechanical and biological functions of several tissues, such as skin, bone, tendons, ligaments, blood vessels, and the cornea [33]. Based on their structure, collagen types in vertebrates can fall into either fibrillar or non-fibrillar groups. Fibril forming collagens (e.g. types I, II, III, V, XI, etc.) show the tendency to aggregate into fibrils that provide tensile strength to and define the shape of tissues. Non-fibrillar collagens (e.g. types IV, IX, XII, XIV, XVI, etc.) do not form fibrils, and are surface associated with fibrillar collagens, interacting with other ECM components such as glycosaminoglycans, proteoglycans, elastin and other cell-interactive proteins such as fibronectin and laminin [33].

All collagens are protein complexes with the basic unit; the triple helix (tropocollagen) composed of three inter-twisted polypeptide $\alpha$-chains. The three $\alpha$ chains are composed of approximately 1000 amino acids, comprised of repeats of the basic triplet glycine-X-Y, with every third position being occupied by glycine and $\mathrm{X}$ and $\mathrm{Y}$ being frequently proline and hydroxyproline, respectively [33]. The proline and hydroxyproline residues are important for the conformation and increased stability of the triple helix, whereas glycine is important in the assembly of the right-handed superhelix structure [34]. In homotrimeric collagens, all three $\alpha$-chains are identical, e.g. types II and III consist of three identical al chains, whereas heterotrimeric molecules consist of two or three different $\alpha$-chains as in the case of Col1, which consists of two $\alpha 1$ chains and one $\alpha 2$ chain [34]. Col1 is characterised by the ability to assemble into highly orientated supramolecular aggregates with a characteristic suprastructure, the typical quarter-staggered fibril-array of diameters between 25 and $400 \mathrm{~nm}$ [35]. Fibrils are defined by a characteristic banding pattern with a periodicity of approximately $67 \mathrm{~nm}$, the D-period, based on a staggered arrangement of individual collagen monomers [36]. Hierarchically, Coll molecules self-assemble into micro-fibrils, fibrils and then fibres.

In bone, Coll dominates the fibrous osteoid organic mass, which is initially secreted by osteoblasts (Figure 1 (I and II)) and eventually undergoes mineralisation, depositing in the architectural form of lamellae or layers in the bone matrix [37]. The same basic nanocomposite building block exists in all bone types: collagen fibril, reinforced by carbonated-hydroxyapatite (CHA) nanocrystals (platelets), with their c-axis [0 0 1] preferentially aligned in parallel to the fibril long axis, and pre-arranged in a matrix presenting a 
periodic array of hole and overlap zones (Figure 1 (III)) [38]. It is generally thought that CHA nanocrystals initially nucleate in the hole zones, eventually outgrowing these and are stored between tropocollagen molecules, thus generating the interpenetrating organicinorganic nanocomposite [6,39]. Mineralised fibrils self-assemble further into higher levels of structure, for instance in parallel arrays that rotate across the concentric lamellae of osteons $[40,41]$ with further hierarchy directed by osteoblasts laying down trabecular and cortical bone macrostructures [40]. Along with the collagen associated water (at $10 \mathrm{wt} . \%$ ), both organic and inorganic components constitute between 20-25 and 65-70 wt.\%, respectively [42]. In addition, small quantities of non-collagenous proteins (NCPs), other collagen types, adhesive and mineral-binding proteins, polysaccharides such as glycosaminoglycans, proteoglycans and glycoproteins are also present $[6,43]$.

Despite recent breakthroughs on its hierarchical structure $[6,44]$, the exact molecular mechanism of collagen mineralisation in bone is as yet not completely understood [45]. Since Coll by itself cannot induce apatite nucleation [46], it is thought that NCPs, such as osteonectin and osteocalcin [47], contribute to the stabilisation of amorphous calcium-phosphate phases as nanoprecursors [48], and to the nucleation and hierarchical assembly of apatite within the collagen scaffold [41]. Therefore, it is generally accepted that the early stages of nucleation are represented by the formation of amorphous calcium-phosphates deposited on the overlap and gap zones of collagen [49]. This is followed by further recruitment of calcium and phosphate ions that induce the spontaneous maturation of the amorphous nuclei into the crystalline apatitic phase [50].

\section{Collagen-based hydrogels}

Highly hydrated collagen (HHC) hydrogels are classically prepared by neutralisation of acid-solubilised collagen monomers that spontaneously self-assemble in vitro at neutral $\mathrm{pH}$ and $37^{\circ} \mathrm{C}$ forming typical $\mathrm{D}$-banded fibrils $[51,52]$. The self-assembly of the initial fibrillar unit involves the amino-terminal non-helical end region, while the lateral fusion of thin fibrillar units are driven by the carboxy-terminal non-helical end [53]. Once neutralised, the collagen solution allows for cell seeding and the molecular self-assembly process forms a mesh-like structure around the cells. One of the earlier defining studies that investigated cell-collagen hydrogel interactions used HHC hydrogels as a model to study encapsulated fibroblast behaviour [54]. It was demonstrated that fibroblasts remodelled the collagen fibrils leading to their denser arrangement, along with the expulsion of water, thereby facilitating cell-modulated gel contraction. This work allowed for the design of a living skin equivalent, which was immunologically tolerated by humans and applied in wound healing. Indeed, HHC hydrogels have been used as the dermal part of Apligraf ${ }^{\star}$ and shown to be of particular benefit in the healing of venous ulcers [55]. Nevertheless, due to their highly hydrated nature, in vitro reconstituted collagen hydrogels lack the hierarchical structural organisation and mechanical properties of the native ECM. The looseness of the fibrillar network also results in their severe fibroblast-driven contraction [56-58]. Along with their initial collagen concentration, the type and density of seeded cells also impact the fibrillar densification process [54]. For example, while non-fibroblastic, transformed or tumour cells show reduced levels of contraction [59], smooth muscle cells or myofibroblasts display greater extents of contraction [56-58]. In addition, other parameters have been found to play critical roles in gel contraction such as a basal level of serum and the presence of growth factors, with an additional dependence on mechanical conditioning [60-62]. Furthermore, the time required to reach a compact ECM-like structure, e.g. similar to that observed in the dermis in vivo, requires over three weeks of culture [63]. Therefore, while HHC hydrogels represent 3D models, the main drawback is their physiological relevance, where the low CFD and poor mechanical properties with respect to native tissues, hinder their suitability for tissue engineering applications.

\section{Cross-linking approaches}

In vivo, collagen fibres possess high tensile strength and resistance to proteolysis, which can be correlated with the number of covalent cross-links present in the molecule [64]. The stabilisation of newly formed collagen fibres occurs with the formation of cross-links between neighbouring collagen molecules through the action of lysine hydroxylase and lysyl oxidase enzymes and through glycation or oxidation by advance glycation end-products [65]. However, extracted and acid solubilised collagens are poorly cross-linked, which leads to weaker reconstituted forms of collagen, characterised by generally low mechanical properties and rapid rates of degradation [64]. To overcome these drawbacks, efforts had been made to generate cross-links in vitro, by forming new covalent bonds between the amino and carboxyl groups of collagen.

Cross-linking (e.g. chemical, physical or enzymatic) approaches have been shown to produce materials with increased mechanical properties (e.g. tensile strength and modulus) for specific applications such as tendon, skin and cornea [66]. However, despite extensive research, to date, there is no accepted standard crosslinking method for the production of collagen-based materials [67]. Furthermore, while the aim of crosslinking is to increase the mechanical properties of collagen scaffolds, some approaches may compromise their biocompatibility by altering their surface 


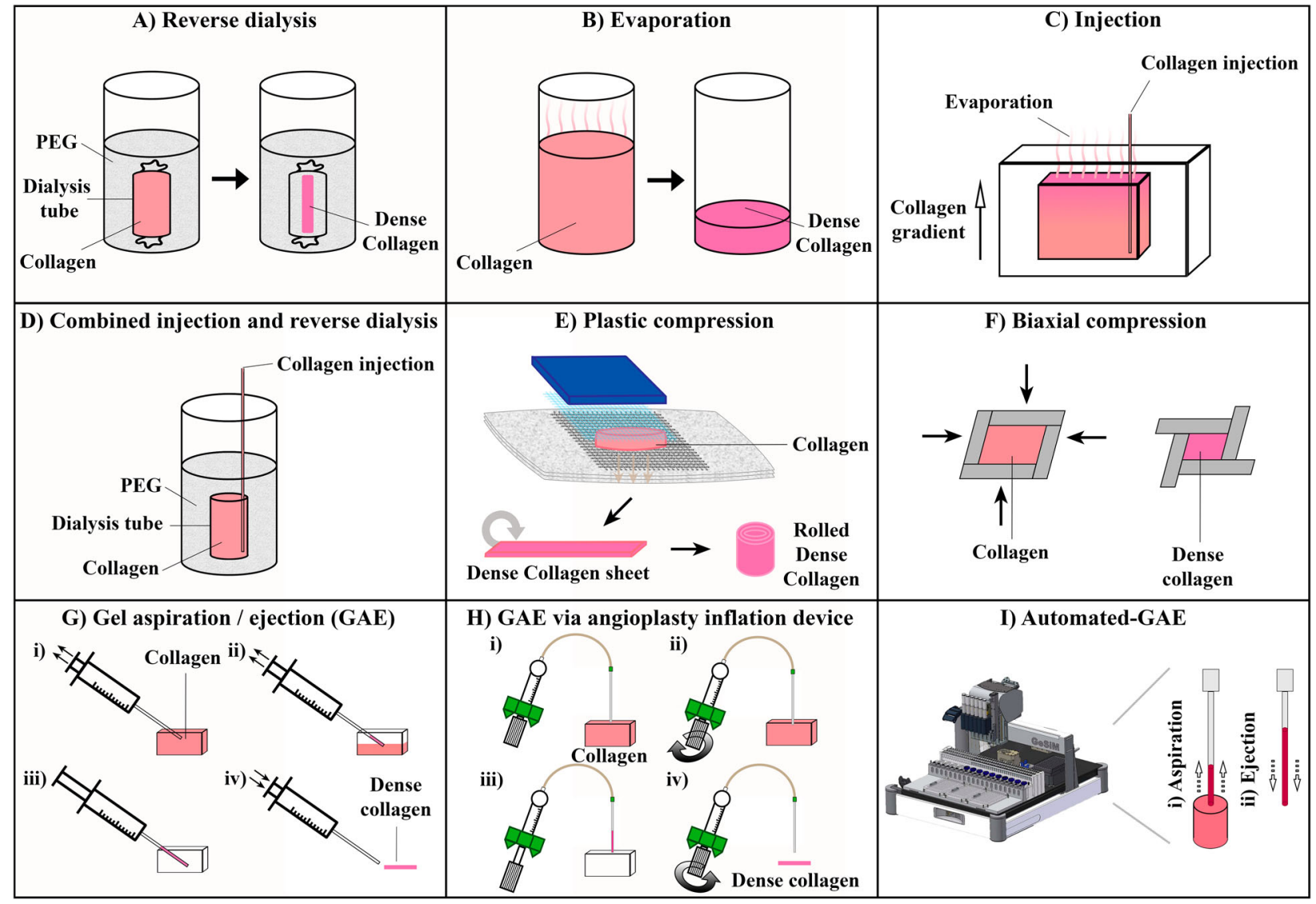

Figure 2. Summary of the approaches to fabricate dense fibrillar collagen hydrogels. (A-D) Pre- fibrillogenesis approaches: (A) Reverse dialysis: aliquots of acidic Col1 monomer solutions at low concentration $(0.3 \% \mathrm{w} / \mathrm{v})$ are concentrated by dialysis against polyethylene glycol (PEG), to reach denser states. Adapted from [71]. (B) Evaporation: acidic Col1 monomer solutions at low concentration (1-5 mg mL${ }^{-1}$ ) are transferred into crystallising dishes and progressively concentrated up to $40 \mathrm{mg} \mathrm{mL}^{-1}$ by slow evaporation of the solvent under a laminar flow bench in sterile conditions. Adapted from [72]. (C) Injection: acidic Col1 monomer solutions at low concentration (1-5 $\mathrm{mg} \mathrm{mL}^{-1}$ ) are slowly and continuously injected into glass microchambers to counteract evaporation and progressively increase the Col1 concentration, leading to large concentration gradients. Adapted from [73]. (D) Combined injection and reverse dialysis: acidic Col1 monomer solution at low concentration $\left(1-3 \mathrm{mg} \mathrm{mL}^{-1}\right)$ is continually injected in a closed dialysis chamber. Reverse dialysis process is against PEG, Col1 solution is concentrated up to $300 \mathrm{mg} \mathrm{mL}^{-1}$. Adapted from [74]. (E-I) Post-fibrillogenesis approaches: (E) Plastic compression: precursor HHC hydrogel is subjected to a load and compacted due to expulsion of the casting fluid resulting in increased CFD [14]. (F) Biaxial compression: precursor HHC hydrogel is compressed along two orthogonal directions to expel the casting fluid in the direction perpendicular to the plane of compression resulting in increased CFD and anisotropy [24]. (G) Gel aspiration-ejection (GAE): precursor HHC hydrogel is slowly drawn into a needle attached to a syringe by applying a negative pressure. Then, a positive pressure is applied to eject an injectable dense collagen hydrogel [23]. (H) GAE through angioplasty inflation device: precursor HHC hydrogel is perforated, aspiration is applied by gently turning the handle of the angioplasty inflation device generating a negative pressure which draws the hydrogel into the needle. Then, a positive pressure is applied to ejected an injectable dense collagen hydrogel by turning the handle of the angioplasty inflation device in the opposite direction [75]. (I) Automated-GAE: precursor HHC hydrogel is aspirated and ejected through an ad hoc system equipped with multiple syringe pumps controlled through a computer [76].

biochemistry in a manner that impedes cell attachment and infiltration and impairs the rate of new tissue ingrowth and remodelling [68-70].

\section{Collagen hydrogel densification techniques}

In order to increase the tissue-equivalency of collagen hydrogels, a number of approaches have focused on their densification; either by increasing the collagen solution concentration pre-fibrillogenesis, or by increasing the fibrillar density post-fibrillogenesis (Figure 2). Among the pre-fibrillogenesis approaches, reverse dialysis [71], evaporation [77], continuous injection [73] and injection coupled with reverse dialysis [78] have been reported, while plastic compression (PC) [14], biaxial compression [24], gel aspirationejection (GAE) [23], and automated-GAE [76] have been reported in the post-fibrillogenesis approaches (Table 2).

\section{Pre-fibrillogenesis densification techniques}

Reverse dialysis (Figure 2(A)) consisted of the slow removal of water from acidic Coll solutions [71], inducing liquid crystallisation and the formation of highly ordered fibril arrays in a cell-free system, in vitro. A 
Table 2. Summary of the main features of the approaches to fabricate dense fibrillar collagen hydrogels.

\begin{tabular}{|c|c|c|c|c|c|}
\hline \multirow[b]{2}{*}{ Technique } & \multirow[b]{2}{*}{ Highly hydrated collagen gels } & \multicolumn{4}{|c|}{ Pre-fibrillogenesis techniques } \\
\hline & & Reverse dialysis & Evaporation & Injection & $\begin{array}{l}\text { Injection couples with reverse } \\
\text { dialysis }\end{array}$ \\
\hline Concentration or CFD & Below $10 \mathrm{mg} \mathrm{mL}^{-1}$ (>1 wt.\% CFD) [54] & Not reported & Up to $300 \mathrm{mg} \mathrm{mL}^{-1}$ ( 30 wt.\% CFD) [79] & Up to $1000 \mathrm{mg} \mathrm{mL}^{-1}$ ( 100 wt.\% CFD) [73] & $\begin{array}{l}\text { Up to } 250 \mathrm{mg} \mathrm{mL}^{-1}(\sim 25 \\
\text { wt.\% CFD) [74] }\end{array}$ \\
\hline Fibrillar organisation & Banded fibrils [54] & $\begin{array}{l}\text { Highly ordered array of fibrils } \\
\text { [71] }\end{array}$ & Regular network or cross-striated fibrils [79] & $\begin{array}{l}\text { From sphrerulite to loose cholesteric to } \\
\text { dense cholesteric, depending on Col1 } \\
\text { solution concentration [73] }\end{array}$ & Cholesteric twist [74] \\
\hline Mechanical properties & Non-reported & Non-reported & $\begin{array}{l}\text { Modulus up to } \sim 78 \mathrm{kPa} \text { (compression test) } \\
\text { with dense collagen hydrogel } \\
\left(40 \mathrm{mg} \mathrm{mL}^{-1}\right)[80]\end{array}$ & Non-reported & Non-reported \\
\hline Cell seeding technique & Within, pre-fibrillogenesis [54] & Non-reported & On top of the scaffold $[72,81]$ & On top of the scaffold [73] & On top of the scaffold [74] \\
\hline $\begin{array}{l}\text { Cell-induced } \\
\text { contraction }\end{array}$ & Severe, up to $99 \%$ contraction [54] & Non-reported & $\begin{array}{l}\text { Reduced and dependent on the Col1 } \\
\text { solution concentration [81] }\end{array}$ & Non-reported & $\begin{array}{l}\text { Not observed in dense } \\
\text { collagen hydrogel of } \\
250 \mathrm{mg} \mathrm{mL}^{-1}[74]\end{array}$ \\
\hline $\begin{array}{l}\text { Tissue potentially } \\
\text { mimicked }\end{array}$ & Skin [54] & Non-reported & Skin [80], fibrolamellar bone [18] & Skin, cornea, bone [73] & Bone [74] \\
\hline Advantages & Easy to produce, cell-friendly environment & Potentially implantable & $\begin{array}{l}\text { Mechanical properties close to native } \\
\text { tissues }\end{array}$ & Useful for fibril arrangements studies & $\begin{array}{l}\text { Control on final concentration, } \\
\text { no scaffold resorption }\end{array}$ \\
\hline \multirow[t]{2}{*}{ Limitations } & Lacks physiological relevance & Small working volume & $\begin{array}{l}\text { Long evaporation time, formation of a } \\
\text { collagen concentration gradient }\end{array}$ & No control on final gel concentration & $\begin{array}{l}\text { The design structure is } \\
\text { subjected to cell } \\
\text { remodelling }\end{array}$ \\
\hline & \multicolumn{4}{|c|}{ Post-fibrillogenesis techniques } & \\
\hline Technique & Plastic compression & Biaxial compression & Gel aspiration-ejection & Automated-GAE & \\
\hline $\begin{array}{l}\text { Concentration } \\
\text { or CFD }\end{array}$ & Up to 25 wt.\% CFD $\left(\sim 250 \mathrm{mg} \mathrm{mL}^{-1}\right)$ [25] & $\begin{array}{l}\sim 10 \mathrm{wt} . \% \text { CFD }\left(\sim 100 \mathrm{mg} \mathrm{mL}^{-1}\right) \\
{[24]}\end{array}$ & Up to 32 wt.\% CFD $\left(\sim 320 \mathrm{mg} \mathrm{mL}^{-1}\right)$ [75] & Up to 12 wt.\% CFD $\left(\sim 120 \mathrm{mg} \mathrm{ml}^{-1}\right)$ & \\
\hline Fibrillar organisation & $\begin{array}{l}\text { Regular, dense network of fibrils with lamellar } \\
\text { structure [14] }\end{array}$ & Highly aligned fibres [24] & $\begin{array}{l}\text { High level of anisotropy with dense, } \\
\text { aligned fibrils }[23,30,75]\end{array}$ & $\begin{array}{l}\text { From low to high level of anisotropy with } \\
\text { increasing density [76]. }\end{array}$ & \\
\hline Mechanical properties & $\begin{array}{l}\text { Modulus up to } \sim 5 \mathrm{MPa} \text { (tensile test) with PC- } \\
\text { generated double compressed dense collagen } \\
\text { hydrogel ( } 23 \text { wt.\% CFD) [25] }\end{array}$ & $\begin{array}{l}\text { Modulus up to } \sim 3 \mathrm{MPa} \text { (tensile } \\
\text { test) [24] }\end{array}$ & $\begin{array}{l}\text { Modulus up to } \sim 4 \mathrm{MPa} \text { (tensile test) with } \\
\text { injectable dense collagen hydrogel ( } 18 \\
\text { wt.\% CFD) [75] }\end{array}$ & $\begin{array}{l}\text { Modulus up to } \sim 0.4 \mathrm{MPa} \text { (tensile test) with } \\
\text { dense collagen hydrogel ( } 6 \text { wt.\% CFD) [76] }\end{array}$ & \\
\hline Cell seeding technique & Within, pre-fibrillogenesis [14] & $\begin{array}{l}\text { On top of scaffold, post- } \\
\text { fibrillogenesis [24] }\end{array}$ & Within, pre-fibrillogenesis [23] & Within, pre-fibrillogenesis [76] & \\
\hline $\begin{array}{l}\text { Cell-induced } \\
\text { contraction }\end{array}$ & $\begin{array}{l}\text { Reduced and dependent of the dense collagen } \\
\text { hydrogel CFD }[29,82]\end{array}$ & Non-reported & Non-reported & $\begin{array}{l}\text { Reduced and dependent on the dense } \\
\text { collagen hydrogel CFD [76] }\end{array}$ & \\
\hline $\begin{array}{l}\text { Tissue potentially } \\
\text { mimicked }\end{array}$ & $\begin{array}{l}\text { Skin [14], nerve [83], bone [28], cartilage [84], } \\
\text { bladder [85], spinal cord [86], cornea [87] }\end{array}$ & $\begin{array}{l}\text { Tendon, ligament, annoulus } \\
\text { fibrosus, meniscus [24] }\end{array}$ & $\begin{array}{l}\text { Long bone }[23,30,75] \text {, tendon [75], nerve } \\
{[23]}\end{array}$ & Long bone, tendon, nerve, skin [76] & \\
\hline Advantages & Particle incorporation, cell-friendly environment & $\begin{array}{l}\text { Particle incorporation, cell- } \\
\text { friendly environment, cell } \\
\text { alignment }\end{array}$ & $\begin{array}{l}\text { SAME as PC, plus fibrillar anisotropy from } \\
\text { the meso- to the nanoscale }\end{array}$ & $\begin{array}{l}\text { Same as GAE, plus reduced human variability, } \\
\text { predictability on gel properties [76] }\end{array}$ & \\
\hline Limitations & $\begin{array}{l}\text { Fragile sheet, highest CFDs negatively impact cell } \\
\text { viability }\end{array}$ & $\begin{array}{l}\text { Anisotropy decreases at the } \\
\text { micro- and nanoscale }\end{array}$ & Small working volume, human variability & $\begin{array}{l}\text { Possible delamination when hydrogels are } \\
\text { assembled in layers [76] }\end{array}$ & \\
\hline
\end{tabular}




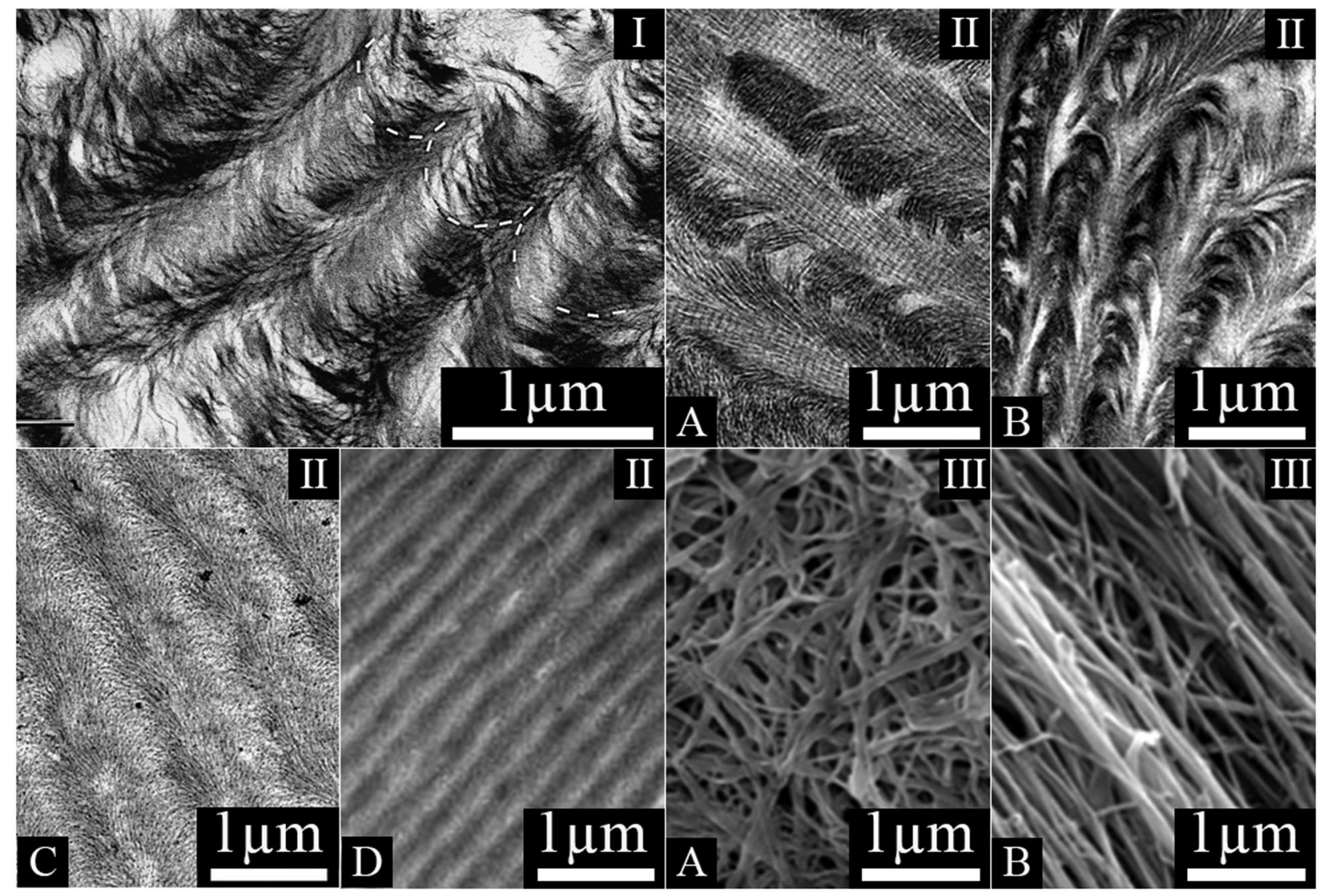

Figure 3. (I) Transmission electron microscopy image of a collagen hydrogel produced by evaporation. Superimposed series of arced patterns, constituted by molecular aggregates. Adapted from [77]. (II) Scanning electron microscopy (SEM) images of collagen hydrogels produced by injection. The width of the cross-striated bundles of fibrils varied along the collagen gradient. Wide bundles are found at more dilute concentrations $(A)$ and narrower bundles with increasing concentrations ( $B, C$, and $D)$. Adapted from [73]. (III) SEM micrographs of collagen hydrogel generated through GAE. Different fibrillar rearrangements can be designed. (A) Lower extent of fibrillar anisotropy was obtained when using a relatively big needle (i.e. $8 \mathrm{G}$ ) while (B) higher extent of fibrillar anisotropy was obtained when using a relatively small needle (i.e. 16G) [76].

progressive and smooth rotation of the molecular axis was observed, where a criss-cross arrangement of fibres of $1-10 \mu \mathrm{m}$ in diameter was detected. The slow evaporation of acid-solubilised collagen solutions exploited the ability of Col1 monomers to self-assemble in liquid crystalline arrays [79], reaching concentrations of up to $300 \mathrm{mg} \mathrm{mL}^{-1}$ (Figure 2(B)) (Figure 3 (I)). Fibrillogenesis was then achieved under ammoniac vapour, resulting in gels with concentration-dependent stiffness that were used to study cellular responses $[16,80]$. Fibroblasts seeded atop proliferated and migrated into the matrix, where the proliferation was repressed by more compact collagen networks [72].

The injection approach (Figure 2(C)) counteracted the evaporation process, thus resulting in dense collagen matrices with concentrations ranging from 5 to $1000 \mathrm{mg} \mathrm{mL}^{-1}$ (Figure 3(II)) [73]. A collagen concentration higher than $80 \mathrm{mg} \mathrm{mL}^{-1}$ was considered as similar to that of the native osteoid. Furthermore, the coupling of continuous injection with reverse dialysis, achieved concentrations of $250 \mathrm{mg} \mathrm{mL}^{-1}$ (Figure 2 (D)) [74]. Regular long-range (in the order of hundreds of microns) stratifications were detected in the bulk, forming a cholesteric twist, where the height of each lamellae corresponded with a $180^{\circ}$ rotation of the fibrillar directions.

\section{Post-fibrillogenesis densification techniques}

PC (Figure 1(E)) consists of the application of a load on HHC hydrogels to controllably expel the casting fluid and predictably increases gel CFD [14]. Gel CFD can reach 25 wt.\% depending on the extent, number (e.g. single or double compression steps) and duration of loading, which is accompanied by an increase in gel stiffness and strength [25]. Simultaneously, the structural features, initially fabricated at the macroscale in HHC gels are shrunk down to the mesoscale. PC enables cell seeding within collagen before fibrillogenesis [14,27,28,88-90], hybridisation through layering $[84,91]$, fibre reinforcement and channelling [92], as well as particle incorporation $[93,94]$. The resultant collagen sheets can be rolled to produce a 3D rod-like spiral construct [25] or around a mandrel thus resulting in a tubular dense collagen hollow cylinder [90]. Attributable to the ability to incorporate cells before compression, PC-generated 
dense collagen hydrogels allowed the investigation of various processing and gel parameters on cellular processes, including their real-time responses to PC [14], CFD [23], hydraulic permeability and stiffness [25,27,30], initial seeding density [28], cell proliferation and differentiation $[75,89,95]$, and their cell-mediated contraction $[82,96]$. Plastically compressed dense collagen hydrogels have been proposed to model a broad range of tissues such as skin $[14,89,97-100]$, nerve [83,101], bone $[27,28,31,84,88,102]$, cartilage $[84,103]$, tendon [104], airways [105], bladder [85,106], spinal cord [86], cornea $[87,107,108]$, joint [109], heart patch [110] and even as a model to study tumour development [111,112] and metastasis [113]. Furthermore, this approach of creating dense tissue equivalent collagen hydrogels has enabled a product: a 3D dense collagen-based cell culture system or $\mathrm{RAFT}^{\mathrm{TM}}$ (Real Architecture for 3D Tissue, Lonza Biosciences Solutions) for use as in vivo-like environments for stem cell, toxicology, oncology and neuroscience research and screening.

The biaxial compression of HHC hydrogels was proposed to produce dense, aligned and porous collagen constructs (Figure 2(F)) [24]. Native connective tissue-like densities of approximately $10 \mathrm{wt} . \%$ were achieved with multiscale fibril-to-fibre alignment. The resulting constructs exhibited highly anisotropic behaviour, where the scaffold modulus along fibre direction was 2-fold greater than that in the transverse direction. Furthermore, cells seeded atop were viable, proliferative and aligned along the direction imposed by the fibrous construct [24].

Gel aspiration-ejection (GAE) is an alternative technique to generate aligned, dense collagen hydrogels. Through the creation of a negative pressure, precursor HHC hydrogels can be easily aspirated into a capillary (e.g. needle), simultaneously inducing their compaction and mesoscale anisotropy. By subsequent reversal of the pressure, 3D rod-like injectable dense collagen hydrogels can be controllably ejected (Figure 2(G)) [23]. The meso- and microscale reorganisation of collagen nanofibrils resulted in their alignment along the direction of the aspiration-ejection, thus enabling the fabrication of hierarchically organised injectable dense collagen hydrogels. GAE can be also applied through a clinically relevant angioplasty inflation device (Figure $2(\mathrm{H})$ ) [75]. By varying the needle gauge number (i.e. from 8 to $14 \mathrm{G}$ ), initial collagen concentrations (i.e. from 2 to $6 \mathrm{mg} \mathrm{mL}^{-1}$ ), and moulds for the HHC precursor preparation, the production of more controlled injectable dense collagen hydrogels of defined CFDs and mechanical properties (ranging from 5 to $32 \mathrm{wt} . \%$ CFDs) was achieved. Hydrogels with higher CFDs and alignments lead to greater polarisation of seeded MSC, which displayed lower metabolic activity, but greater expression of osteogenic markers. This may be due to an environment, which was more similar to the native osteoid thus promoting the osteogenic differentiation of seeded MSCs [75]. More recently, GAE has been further developed and performed through an automated system thus allowing a reproducible highthroughput gel production (Figure 2(I)) [76]. The high level of reproducibility obtained through automated-GAE, led to the development of a mathematical relationship used to predict and tailor hydrogel density and anisotropy, seeded cell response, and seeded cell remodelling activity in order to meet the needs of a target application [76]. In particular, the extent of fibrillar rearrangement can be tuned to generate randomly oriented (Figure 3(III, A)) to highly anisotropic hydrogels (Figure 3(III, B)). Additionally, seeded fibroblasts were polarised along the collagen fibril direction. Interestingly, gels of different shapes and geometries (e.g. cylindrical, quadrangular, and tubular) can be used as mini-tissue building blocks for the design of intricate structures with possible uses as tissue models or organoids. This may represent a possible novel approach for the 3D bioprinting of collagen-based bioinks [76].

\section{Pre- versus post-fibrillogenesis techniques, the native ECM-mimicking approach}

Although several approaches have been proposed to design an osteoid-like model through collagen densification, to date, there is no 'gold standard'. In this review, techniques have been divided into either preor post-fibrillogenesis approaches based on when the densification occurs. The main differences between these two categories consist in their cellular applications and in their ability to recreate single or multiscale structural levels of tissues. In the prefibrillogenesis approaches, cells can only be seeded atop, whereas in the post-fibrillogenesis approaches cells can be seeded within scaffolds. When cells are seeded atop, their penetration within the gel can require weeks of culturing and results in unpredictable changes in gel microarchitecture due to cell-mediated remodelling [81]. This may represent a limitation in clinical applications where the tailoring of a target tissue microarchitecture is key. Furthermore, the scaffold density dictates the extents of cell penetration and proliferation, thus limiting cellular activity to the scaffold outer layers $[81,114]$. On the other hand, a scaffold in which cells are homogenously seeded within may better recapitulate the native structure of a target tissue. In the post-fibrillogenesis approaches cells are seeded before gelation thus allowing for their attachment to the collagen fibrils $[14,23,24]$. Densification of the scaffold, through controlled fluid expulsion, aims to reach native tissue densities without harming seeded cells [14]. Furthermore, depending on the densification route (i.e. type and direction of loading), cell density, morphology and polarisation can be 
imparted. This is a distinct characteristic of the postfibrillogenesis approaches, which cannot be replicated in the pre-fibrillogenesis approaches. However, cell incorporation in the former may also lead to cellmediated gel contraction thus resulting in their loss of proliferation and changes in scaffold architecture. Therefore, parameters such as final gel density, initial seeded cell density and forces exerted by different cell types, must be meticulously considered for a particular application.

Post-fibrillogenesis approaches focus on microenvironmental design, thus their architectures are able to replicate the native tissues only at the microscale $[14,23,24]$. Therefore, from a structural viewpoint, these techniques focus on controlling the fibrillar rearrangement. PC generates random fibrillar arrangements [14], whereas different levels of anisotropy can be imparted to fibrils through biaxial compression [24] and GAE [23]. In particular, biaxial compression gives control over the extent of fibrillar anisotropy only at the mesoscale [24], while GAE exerts nano-tomesoscale control, in a fully predictable manner $[23,76]$. However, bone is characterised by multifaceted hierarchical levels where long-range interactions are essential in its development and turnover [115]. For this reason, osteoid models generated through postfibrillogenesis can be used when the study of processes related to bone activity occurring at the nano-to-microscale are of interest and higher level of tissue organisation are not necessary. On the other hand, prefibrollogenesis approaches have been shown to reproduce not only microenvironments, but also higher level of fibrillar organisation, e.g. bundles of different arrangements closely mimicking those of native bone lamellae [74]. Thus, these approaches represent a better alternative when processes involving higher hierarchical levels than the microscale are of interest.

In sum, although each approach presents limitations, the best technique can be chosen depending on the research aim. While pre-fibrillogenesis approaches may be better in mimicking the structural features of a tissue from an acellular point-of-view, post-fibrillogenesis approaches can be powerful in investigating the effect of scaffold microarchitectural cues on seeded cellular responses.

\section{Acellular approaches to mineralise collagen}

A key requirement in the biomimetic mineralisation of bone is the recreation of the geometry and architecture of its native ECM [116]. For this reason, Coll, the native building material of the osteoid, represents a powerful tool to mimic the ECM of bone [117]. Therefore, the techniques described so far aim to recreate different architectures resembling those of the native osteoid. However, since Coll alone poorly mineralises, strategies to overcome this limitation need to be considered when attempting to mimic the biomineralisation process [46]. For this reason, once the desired architecture is created, a following key step consists of promoting its mineralisation. In the native condition, the deposition of the mineral phase occurs within (intra-fibrillar) and between (inter-fibrillar) collagen fibrils [118]; processes that can be recreated using dense Coll scaffolds.

\section{Pre-fibrillogenesis-based approaches to acellularly mineralise collagen}

The pre-fibrillogenesis approaches rely on the fact that Col1 molecules spontaneously organise to form liquid crystalline phases at high concentrations in acidic solutions, where the concentration is the key parameter to determine to final fibrillar arrangement [16]. Indeed, as a function of concentration, collagen monomers assemble in successive arrangements corresponding to defined geometries (Figure 3). Once the desired osteoid mimicking architecture is generated by regulating the initial Coll concentration, the scaffold is then mineralised. Strategies based on the co-precipitation of calcium-phosphate precursor [18,19], polymerinduced liquid precursor (PILP) process [119], and immersion in simulated body fluid (SBF) solution [120] have been proposed.

A mineralised osteoid has been produced through a co-precipitation process based on a two-phase strategy. The first phase consisted of the co-precipitation of both calcium-phosphate salts and pure Coll monomers, followed by the addition of polyaspartate, an acidic calcium-binding polymer. The second phase consisted of dialysing the resulting Col1 based solution to yield dense collagen-CHA scaffolds [18]. The hydrogels were characterised by densely packed fibrils that were organised helicoidally, resembling the structure of osteons, where the CHA was inter-fibrillarly deposited within the matrix [18]. Similarly, co-precipitation can be followed by an evaporation-based densification process. Coll monomers subjected to evaporation reached concentrations of up to $300 \mathrm{mg} \mathrm{mL}^{-1}$, resulting in a suprafibrillar organisation with an arch shape pattern, similar to those found in compact bone [77]. The nucleation of CHA crystals was then achieved by coupling evaporation with co-precipitation, resulting in their $c$-axis alignment with the axial direction of the collagen fibrils; similar to partially demineralised human bone [19]. The dense collagenous matrix also controlled the CHA crystal size, where the resulting mineralised collagen fibrils were in the $\sim 100-300 \mathrm{~nm}$ range and similar to those found in native tissue. On the other hand, without the matrix confinement, CHA crystals were found to be larger [18].

PILP is another process to mineralise collagen in which a liquid phase mineral precursor is intra-fibrillarly penetrated within collagen [119]. Here, the 

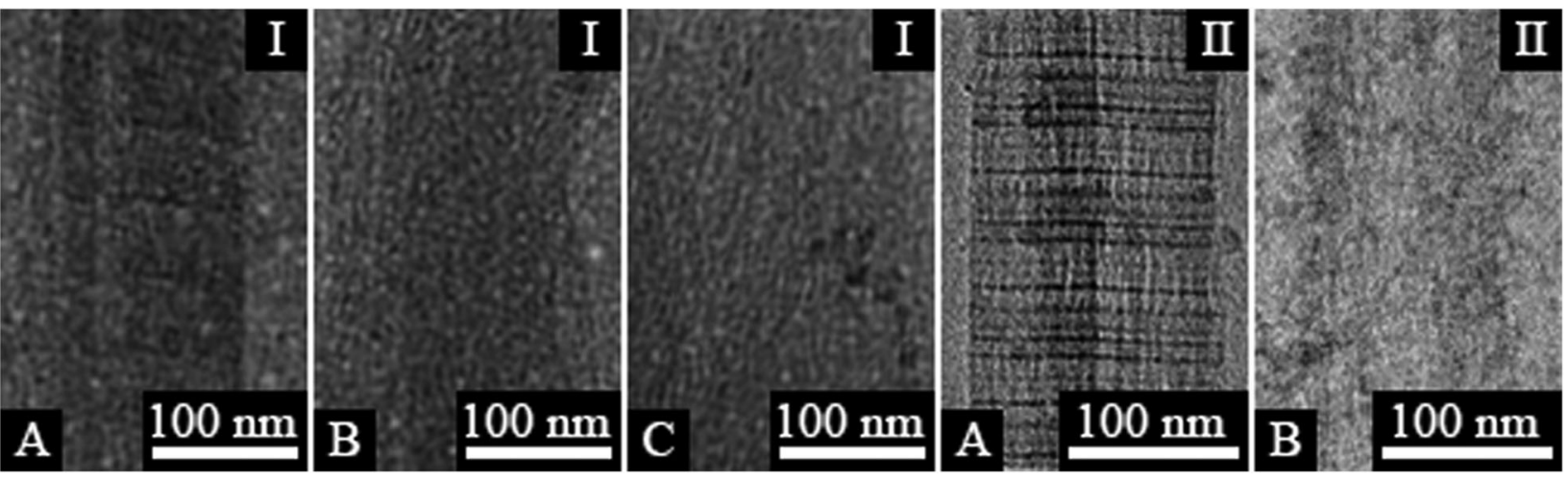

Figure 4. (I) Transmission electron microscopy (TEM) image of a mineralised dense collagen hydrogel produced through the coupling of continuous Col1 monomer injection and reverse dialysis, followed by immersion in SBF. Cryo-TEM images of collagen fibrils in the collagen-CHA soaked in SBF matrix may reflect different degrees of mineralisation, low $(A)$, intermediate (B) and high (C), supported by disappearance of the banding pattern. Apatite crystals isolated from the collagen matrix (arrows) appear with irregular edges and in the same size range as those found in bone. Adapted from [120]. (II) Scanning electron microscopy analysis of (A) PC Af dense collagen hydrogel at day 14 in SBF depicted inter-fibrillar mineral formation. (B) Cryo-TEM nanographs of (B) Af as made and $(C)$ after $24 \mathrm{~h}$ exposure to SBF. Intra-fibrillar mineralisation was evident after exposure to SBF, which masked the collagen Dbanding structure. Adapted from [122].

addition of a negatively charged molecule to a mineralisation solution induces or stabilises an amorphous, highly hydrated precursor to the mineral, simultaneously delaying the nucleation and growth of crystals to form a metastable solution. Through this, intra-fibrillar collagen mineralisation can be realised in vitro, where CHA nanocrystals are [001] aligned within collagen fibrils, thus mimicking the nanostructure of natural bone [119]. Dialysis generated dense collagen hydrogels $\left(100-400 \mathrm{mg} \mathrm{mL}^{-1}\right)$, treated with PILP, generate highly mineralised hierarchical composites with lamellar bone-matching compositions [121]. Parallel arrays of banded collagen fibrils extended over several microns in non-mineralised sections, where their cholesteric twisting reflected a lamellar-like microstructure [121].

By coupling continuous Coll monomer injection with reverse dialysis, it has been demonstrated that collagen alone can initiate and orientate CHA mineralisation, in vitro, through immersion in SBF [120]. CHA nanocrystals were preferentially aligned along the collagen fibril main axis, similar to that observed in bone. The detection of collagen banding pattern indicated that crystals were within the gap regions of fibrils, thus confirming their intra-fibrillar mineralisation. On the other hand, in cases where the collagen fibril banding disappeared, low, intermediate and high degrees of mineralisation were reported (Figure 4(I, A, B and C)). Furthermore, the $3 \mathrm{D}$ organisation of the collagen network and gel structure, controlled the shape, size, and spatial distribution of the apatite crystals [120].

\section{Post-fibrillogenesis-based approaches to acellularly mineralise collagen}

The post-fibrillogenesis approach relies on the controlled expulsion of the casting fluid by applying pressure to increase the CFD and to modulate gel architecture. Through this, scaffolds characterised by microarchitectural and micromechanical similarities with the native osteoid can be produced [75]. Postfibrillogenesis-derived dense collagen hydrogels are routinely mineralised by immersion in SBF. Additionally, to modulate the extent of mineral deposition, approaches based on the variation of the CFD [26], or of the electrostatic environment [122], and on the incorporation of bioactive molecules [94,123-124] have been proposed.

PC-derived scaffolds of between 1 and 14 wt.\% CFDs were immersed in SBF to investigate whether CHA nucleation on collagen fibrils was influenced by a more constrained microenvironment [26]. Increased CFD led to greater fibril entanglement, fibril-to-fibril contact points and reduced roughness, which facilitated increased levels of CHA formation. Morphologically, CHA clusters inter-fibrillarly nucleated, with inner sections of dense collagen gel rolls presenting greater extents of bulk mineralisation [26]. Dense collagen gel electrostatic properties have also been modulated by inducing their fibrillogenesis at different $\mathrm{pH}$ [122]. Gels richer in negative charge $(\mathrm{Af}, \mathrm{pH}=9)$ resulted in intra- and inter-fibrillar mineralisation in SBF (Figure 4(II, A and B)).

The incorporation of bioactive particles, before gelation and densification, have been shown to promote mineral formation, by acting as anchoring points for CHA nucleation and growth [125]. The incorporation of micron-sized bioactive glass $(\mu \mathrm{BG})$ particles of a similar formulation to Bioglass ${ }^{\otimes} 45 \mathrm{~S} 5$, into PC-generated dense collagen hydrogels enhanced their $3 \mathrm{D}$ biomineralisation in SBF, resulting in their ductile-brittle transition [94]. The incorporation of nano-sized bioactive glass (nBG) showed higher mineralisation potential compared to $\mu \mathrm{BG}$ leading to homogeneous 
inter-fibrillar CHA formation within 3 days in SBF [126]. BG incorporation has also led to the mineralisation of dense collagen gel scaffolds, in vivo, post-subcutaneous injection [30]. At day 21 implantation, host cell infiltration into the acellular gels led to ectopic bone formation with osteoblastic and osteoclatic activity, demonstrating the osteoinductive nature of the scaffolds [30].

Negatively charged silk polypeptides have also led to the rapid and bulk biomineralisation of dense collagen gels, by mimicking the role of NCPs in the in vivo mineralisation process [48]. Derived from the a-chymotrypsin digestion of silk fibroin, Cs polypeptides (Mw ranging from 2 to $10 \mathrm{kDa}$ ) have the ability to rapidly form CHA when immersed in SBF [93]. Cs incorporated PC dense collagen hydrogels indicated the formation of an apatitic phase after only $6 \mathrm{~h}$ in SBF $[23,93]$, and by day 7 in SBF, more than half of the hydrogel was inter-fibrillarly mineralised. The progress of mineralisation in PC-generated dense collagen-Cs hydrogels, also led to a transition from soft-to-hard tissue-like response to compressive stress [93]. Similar effects have been shown when sericin fragments were incorporated in injectable dense collagen hydrogels [124]. After immersion in SBF, sericin incorporated hydrogels exhibited a time-dependent amorphous-to-crystalline phase transition. At 14 days in SBF, more than $90 \%$ of the osteoid-mimicking structure was mineralised through $\mathrm{CHA}$ deposition [124].

\section{Reproducing the inter- and intra-fibrillar mineralisation process in densified collagen}

In vivo, the mineralisation process in calcified tissues consists of the nucleation and growth of mineral crystals in both unconfined and confined spaces. The arrangement of collagen molecules creates a nanoscaled porous platform for the mineralisation of calcium-phosphate particles. The appropriate spaces for intra-fibrillar mineralisation are provided by narrow channel-like gap regions that drive the formation of oriented apatite crystals. Through inter-fibrillar mineralisation, apatite crystals, without a specific orientation, also grow in aggregates in the unconfined extrafibrillar spaces of collagen matrix [127]. Since collagen possesses characteristic 3D stereochemical amino-acid side chains with an electrical charge distribution, it may also provide nucleation sites for mineralisation [42]. Therefore, a number of key points of the mineralisation process, such as the location of nucleating sites in the collagen triple helix, and its conformational changes due to mineralisation could be tackled using either pre- or post-fibrillogenesis densified collagen hydrogels. Since CHA is composed of calcium ions surrounded by both phosphate and hydroxide ions, the scaffold mineralisation strategies described above have relied on their exposure to calcium-phosphate based solutions [50].

Interestingly, strategies based on the incorporation of bioactive materials (i.e. BG and silk derived fragments) in dense collagen only reproduced their interfibrillar mineralisation. By providing the anchoring points for the complexation of calcium and phosphate ions, these materials trigger bulk mineral deposition and growth. However, the lack of intra-fibrillar mineralisation may be due to a disorganised distribution of these anchoring points within the collagenous matrix, which may not be located in the gaps and overlap zones, e.g. due to steric hindrance. To achieve collagen intra-fibrillar mineralisation, there is a large consensus in the literature regarding the necessity of using calcium ion binding polymers that mimic the role of aspartic and glutamic acid-rich NCPs [120]. These amino-acids have high affinity for calcium ions [128]; critical for intra-fibrillar collagen mineralisation and CHA crystal-collagen fibril co-alignment [120]. The addition of polyaspartic acid into mineralisation solutions results in the formation of liquid phase amorphous mineral precursors that infiltrate the collagen fibrils that then solidify to form CHA nanocrystals, filling the gaps and overlaps zone of collagen [129]. Another important aspect in developing a system that allows intra-fibrillar mineralisation is the collagen charge distribution; scaffolds intrinsically richer in negative charge have been shown to induce calciumphosphate formation $[130,131]$. In particular, the positively charged amino end of the collagen molecule, may become negatively charged when cast at alkaline $\mathrm{pH}$. This would provide a net negative charge at the gap and overlap zones that complex with calcium ions to trigger mineral formation. This may explain why this strategy results in both inter- and intra-fibrillar mineralisation of dense collagen hydrogels.

\section{Cell-mediated mineralisation}

The dense collagen osteoid model can be also mineralised by exploiting the ability of osteoblastic cells to deposit and mineralise their secreted ECM when seeded either atop or within a scaffold. Cell-scaffold interactions play critical roles in mineralisation, where the scaffold must provide the appropriate environment to support cellular function.

\section{Cell-mediated mineralisation of pre- fibrillogenesis-derived dense collagen hydrogels}

The effect of hydrogel density on modulating the extent of cell-mediated mineral deposition was evaluated by comparing the response of human osteoblasts seeded on top of 5 and $40 \mathrm{mg} \mathrm{mL}^{-1}$ evaporation-based dense collagen hydrogels. Cells seeded on top of $5 \mathrm{mg} \mathrm{mL}^{-1}$ hydrogels assumed characteristic cuboidal 

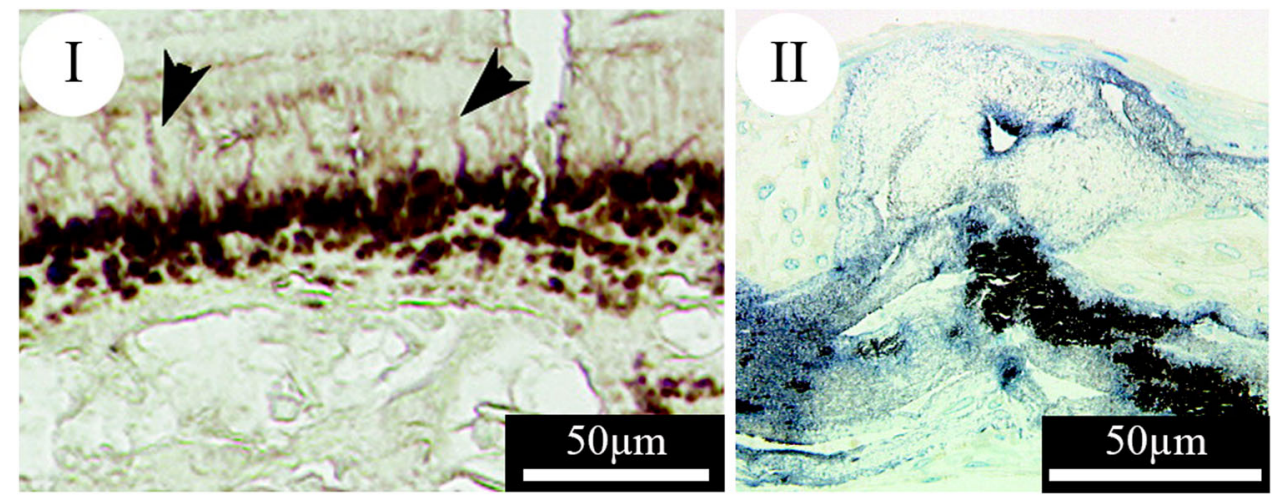

Figure 5. (I) Metalloproteinases release by osteoblasts infiltrated within the collagen hydrogels as an indicator of the cell action creating spaces for the osteoprogenitor cells. Metalloproteinases are diffused through the spaces of a $5 \mathrm{mg} \mathrm{mL}^{-1}$ hydrogel, visible in the form of stained tracks (A, arrowheads). Adapted from [133]. (II) Histological slices of densified collagen hydrogels produced through post-fibrillogenesis approaches and stained with von Kossa staining for mineral detection. Mineral deposition after 4 weeks in culture carried by cell-seeded PC-generated dense collagen hydrogel. Adapted from [88].

epithelium-like morphologies and expressed alkaline phosphatase and osteocalcin, indicating an osteoblastic phenotype. In contrast, flat and elongated cellular morphologies were observed when seeded on $40 \mathrm{mg} \mathrm{mL}^{-1}$ hydrogels. Furthermore, cells were only able to penetrate the less dense scaffolds as was observed with fibroblasts [81,132]. However, osteoblasts seeded on $40 \mathrm{mg} \mathrm{mL}^{-1}$ hydrogels demonstrated enhanced cell proliferation, compared to those seeded on less dense hydrogels [21]. A time-dependent increase in mineralised surface cell-secreted matrix was also detected confirming their osteoblastic function. The performance of human primary osteoblasts seeded on collagen hydrogels of 5 or $40 \mathrm{mg} \mathrm{mL}^{-1}$ densities was further evaluated through implantation in calvaria defects in rats (Figure 5(II)) [114]. Interestingly, attributable to pores created by foreign body giant and endothelial cells, the penetration of osteoprogenitor cells into $40 \mathrm{mg} \mathrm{mL}^{-1}$ scaffolds was observed, ultimately resulting in greater extent of new bone formation. Collagen degradation was also dependent on its initial concentration, with greater reduction in volume reported in $5 \mathrm{mg} \mathrm{mL}^{-1}$ gels [133].

\section{Cell-mediated mineralisation of post- fibrillogenesis-derived dense collagen hydrogels}

The post-fibrillogenesis approaches are characterised by their ability to seed cells as a part of the hydrogel processing route [14,23]. In particular, cells can be homogeneously seeded in 3D within dense collagen hydrogels without significantly reducing resident cell viability. PC-fabricated dense collagen hydrogels are characterised by controllable compressive modulus values (i.e. range of $20-40 \mathrm{kPa}$ ), similar to that of an osteoid, and therefore, can be used to study mineralised tissues [134]. Similarly, GAE-produced hydrogels are also characterised by osteoid-like microarchitectural properties [23]. The effects of gel CFD [88,135], fibrillar alignment $[23,75]$ and hydraulic permeability [29] on modulating the seeded cell growth, osteoblastic differentiation, and mineral deposition have been investigated. Furthermore, strategies based on the incorporation of bioactive molecules with osteoinductive, -conductive, and -stimulative properties have been explored [123,124,136,137].

Pre-osteoblast-seeded PC-generated dense collagen hydrogels (with CFD > $10 \mathrm{wt} . \%$ ) showed upregulation of osteogenic genes, demonstrating their differentiation and matrix mineralisation, which in turn caused a further increase in the scaffold's Young's modulus [135]. Similarly, a mouse calvarian preosteoblast cell line (MC3T3-E1) seeded into PC-generated dense collagen scaffolds underwent osteoblastic differentiation followed by nascent collagen deposition and subsequent time-dependent mineralisation (Figure 5(II)) [88].

The effect of PC load and duration on scaffold microstructure and osteogenic outcome has been investigated through hydraulic permeability, which can be related to scaffold microstructural (e.g. fibre diameter and pore size) and mechanical properties, cell-scaffold interactions, as well as oxygen flow, and nutrient diffusion [29]. Increasing levels of PC led to scaffolds with increased CFD and compressive modulus [82], whereas it decreased the hydraulic permeability; coinciding with a reduction in cell-induced matrix contraction. This was attributed to a reduction in cell migration and proliferation observed when MSCs initiate their differentiation pathway. Indeed, seeded MSC proliferation, osteogenic differentiation and matrix mineralisation was increased in osteogenic medium, demonstrating that hydraulic permeability regulated the differentiation of seeded stem cells [29].

PC-generated dense collagen hydrogels were also shown to be a powerful model to explore other mineralised tissues, such as those present in teeth [102]. Seeded human exfoliated tooth pulp-derived dental 
pulp stem cells readily underwent differentiation, while secreting mineralisation-regulating proteins and scaffold mineralisation. Follow-up in vivo studies in murine cranial critical-sized defects confirmed the bone regeneration potential of dental pulp stem cell seeded-PC dense hydrogels [31]. At day 28 postimplantation, and in contrast to acellular gels, cellseeded dense collagen hydrogels displayed osteogenic effects, thereby enhancing bone healing. Cell-seeded dense collagen hydrogels promoted the osteoconduction, where along with the presence of tartrate-resistant acid phosphatase positive osteoclasts in and around the scaffolds, there was active and restored matrix turnover within the defect [31].

The incorporation of other biopolymers $[84,89,136,138]$ or bioinorganics $[94,123]$ into PC-generated dense hydrogels represents a strategy to accelerate seeded cell osteoblastic differentiation and matrix mineralisation. For example, the incorporation of chitosan, a glycosaminoglycan-mimicking analog, increased alkaline phosphatase activity, along with mineral deposition by seeded MC3T3-E1 pre-osteoblasts [139]. Nano-BG incorporated into PC-generated dense collagen hydrogels increased the osteoblastic differentiation of seeded MC3T3-E1 cells in the absence of osteogenic supplements [123]. Similarly, the incorporation of negatively charged, silk-derived polypeptides [137] and sericin [124], within MSCseeded dense collagen hydrogels led to the upregulation of osteo-related markers and enhanced cell-mediated mineral deposition.

By comparing PC- and GAE-generated dense collagen hydrogels, the fibrillar architecture was also investigated as a possible parameter affecting the osteoblastic outcomes of seeded MSCs [23]. Interestingly, MSCs seeded in injectable dense collagen expressed lower levels of metalloproteinases and higher levels of tissue inhibitor of metalloproteinase compared to cells seeded into PC-generated hydrogels. This suggested a reduced cell remodelling activity, which was correlated with the earlier onset of the osteoblastic differentiation induced by the anisotropy of the scaffolds [23,75]. Furthermore, accelerated cellinduced mineralisation in injectable dense collagen hydrogels suggested that the immediate cell alignment imparted by the GAE process potentially accelerated MSC osteoblastic differentiation [23].

\section{The osteoid-model microarchitecture as a driving parameter for bone cell activity}

In vivo, osteoblastic cells deposit the osteoid, which are then involved in its mineralisation, by regulating the local calcium and phosphate concentrations to promote apatite mineralisation [128]. Biomineral nucleation and growth requires a local environment with sufficient supersaturation by its precursors. It is thought that
CHA is first nucleated within osteoblast-secreted vesicles, which then grows and breaks through the vesicle into the surrounding extracellular fluid. This suggests that mineral formation is initially also a cell-regulated process, while its propagation is mediated by collagen in the ECM [140]. However, vesicles are not the only sites of mineralisation as a variety of matrix proteins, such as NCPs, nucleate and control the growth and agglomeration of these nanocrystals [141].

The cellular strategies described above are inspired by the in vivo biomineralisation process. Indeed, the propagation and maturation of seeded bone cellinitiated mineral deposition is mediated by the osteoid model architecture as dictated by the densification technique. Bioactive molecules [142-147] have also been used to promote mineral deposition and maturation, while other NCP-mimicking molecules have been shown to mediate mineral formation $[93,94,123]$. The main difference in cell-mediated mineralisation of osteoid models designed through either pre- or post-fibrillogenesis densification approaches, is the deposited mineral distribution. In vitro results have shown that in pre-fibrillogenesis, cells can only be seeded atop, thus limiting mineral deposition to the scaffold outer layer, whereas in post-fibrillogenesis, cells can be seeded within the hydrogel thus allowing a homogeneous mineral deposition. However, in vivo results have shown that evaporation-generated scaffolds can be colonised and degraded by non-osteoblastic cells post-implantation, playing a key role in mineralisation [133]. Scaffold degradation was modulated by hydrogel density as can be controlled by initial collagen solution concentration and/or evaporation time. This may be useful in some clinically relevant applications where defects in load-bearing bones may require scaffolds with slower degradation rates during the healing process $[148,149]$. On the other hand, non-load bearing applications such as those in thin bones or in the cranium, may require more rapid rates of scaffold degradation and the promotion of a new bone formation, where the mechanical properties may be less critical [150].

The homogeneous cell distribution within postfibrillogenis-generated dense collagen hydrogels can be amenable to tailoring the microenvironment to modulate cellular activity, e.g. the collagen fibril (or bundle) diameter $(\sim 100 \mathrm{~nm})$ can be important in affecting cell morphology and migration. The scaffold pore size distribution represents an additional factor, e.g. PC-generated dense collagen hydrogels are characterised by heterogeneous pores $(1-20 \mu \mathrm{m})$; similar in magnitude to collagenous tissues, in vivo. The compressive modulus, which is dictated by the scaffold CFD, regulates cell adhesion, differentiation, morphology and migration $[134,149,150]$. Additionally, the hydraulic permeability of the dense hydrogel has to be considered in order to provide appropriate flow 
of nutrients and catabolites necessary for cellular activities [29], which can be further explored in GAE-generated dense collagen hydrogels. Cellular activity is known to be limited to the $\sim 200-400 \mu \mathrm{m}$ outer perimeter of a hydrogel [151]. While this does not represent an issue in PC-generated gels (sheets of $\sim 100 \mu \mathrm{m}$ thick), this may be critical in rod-shaped injectable dense collagen hydrogels with a range of diameters. Nevertheless, GAE-generated dense collagen hydrogels demonstrate clear advantages of having an anisotropic structure that influences osteoprogenitor cell behaviour. Indeed, seeded MSCmediated remodelling of PC-generated hydrogels led to a shift from an isotropic to an anisotropic fibrillar matrix [123]. On the other hand, cell-mediated remodelling of GAE-generated dense collagen hydrogels was marginal, while the onset of seeded MSC-osteoblastic differentiation and their mineral deposition was accelerated $[23,75]$. This may be due to the anisotropy of the microenvironment which better mimic the native osteoid thus requiring less cell-remodelling.

\section{Discussion}

Osteoid mimicking dense collagen gels generated through either pre- or post-fibrillogenesis densification approaches have been widely explored to mimic and reproduce the native biomineralisation process. Although the aim of bone tissue engineering is to develop mechanically stable ECM mimicking scaffolds to support regeneration, and through this provide a greater understanding of the processes occurring during biomineralisation at multiple hierarchical levels, the densification approaches discussed above have so far only focused on one or a few levels of tissue organisation. This not only limits their use as multi-hierarchical tissue models, but also as temporary grafts for small defects characterised by welldefined and reproducible architectures. Thus, it can be proposed that so far, the main gap that has been overlooked relies on the simultaneous reproduction of several hierarchical levels, which would better represent the organ bone. Another important aspect that has been neglected when the majority of the densification techniques are applied, is their reproducibility. These techniques are user dexterity-dependent, thus leading to variations in material quality and properties among users of different levels of expertise. Therefore, standardised approaches with protocols that can be routinely applied in a completely automated manner through ad hoc platforms for the production of scaffolds are highly desirable. To this end, the 3D printing of tissue-like collagen bioinks represents a great deal of interest for the high-throughput engineering of in vitro tissue models and organoids. However, current approaches such as direct extrusion, ink-jet and laser-based 3D bioprinting are generally not suitable for reproducing the hierarchical architecture of tissues based on fibrous proteins. The 3D printing of collagen hydrogels is particularly challenging due to their narrow printability range, where protein structure, seeded cell viability, and bioactivity of incorporated biomolecules all need to be maintained within physiological boundaries. Therefore, the use of collagen hydrogels in bioprinting is severely limited due to its highly hydrated nature, lack of structural control, low mechanical properties, and premature gelation during the printing process. To overcome these drawbacks, the $3 \mathrm{D}$ printing of collagen often relies on chemical crosslinking, or on the use of temporary or long-term supporting materials, which deviates the ability to generate ECM-like structures.

The recent automation of GAE in generating dense collagen gels represents a promising alternative in the $3 \mathrm{D}$ printing of fibrous proteins such as collagen. Collagen bioinks with target properties can be predictably designed; without human variability. The use of automated-GAE for the production of bone tissue engineering scaffolds can potentially be used to investigate the biomineralisation process from a new perspective. In particular, collagen bioinks with unique properties could be printed and assembled to resemble multiple hierarchical levels of bone. For example, bioinks characterised by a less dense and random fibrillar structure, loaded with bone marrow cells could be printed to reproduce spongy bone. This core structure could be surrounded by more compact bone-like architectures composed of mineralised bioinks with different fibrillar arrangements (i.e. ordered and disordered arrays) disposed to recreate suprastructures such as lamellar bone or fibrolamellar units (Figure 6). Therefore, the production of bone organoids could be used to investigate the long-range interactions occurring among different hierarchical levels of the native tissue during the biomineralisation process. In addition, multiple tissue interfaces could be also modelled, e.g. mineralised collagen bioinks could be assembled to recreate a bone-like structure and connected to layered bioinks characterised by high levels of anisotropy, thus mimicking the structures of ligaments or tendons. Similar concepts could be applied to the osteochondral interface where a layer of plastically compressed collagen resembling the features of cartilage, could be placed in between two mineralised collagen bioinks mimicking bone. Moreover, the ability to simultaneously recreate several hierarchical levels of bone may represent a new breakthrough approach to investigate not only physiological, but also pathological conditions, such as in cancer metastasis and potential therapy.

In terms of potential clinical applications, the shortterm objective should focus on the development of osteoid-like models mineralised through acellular 


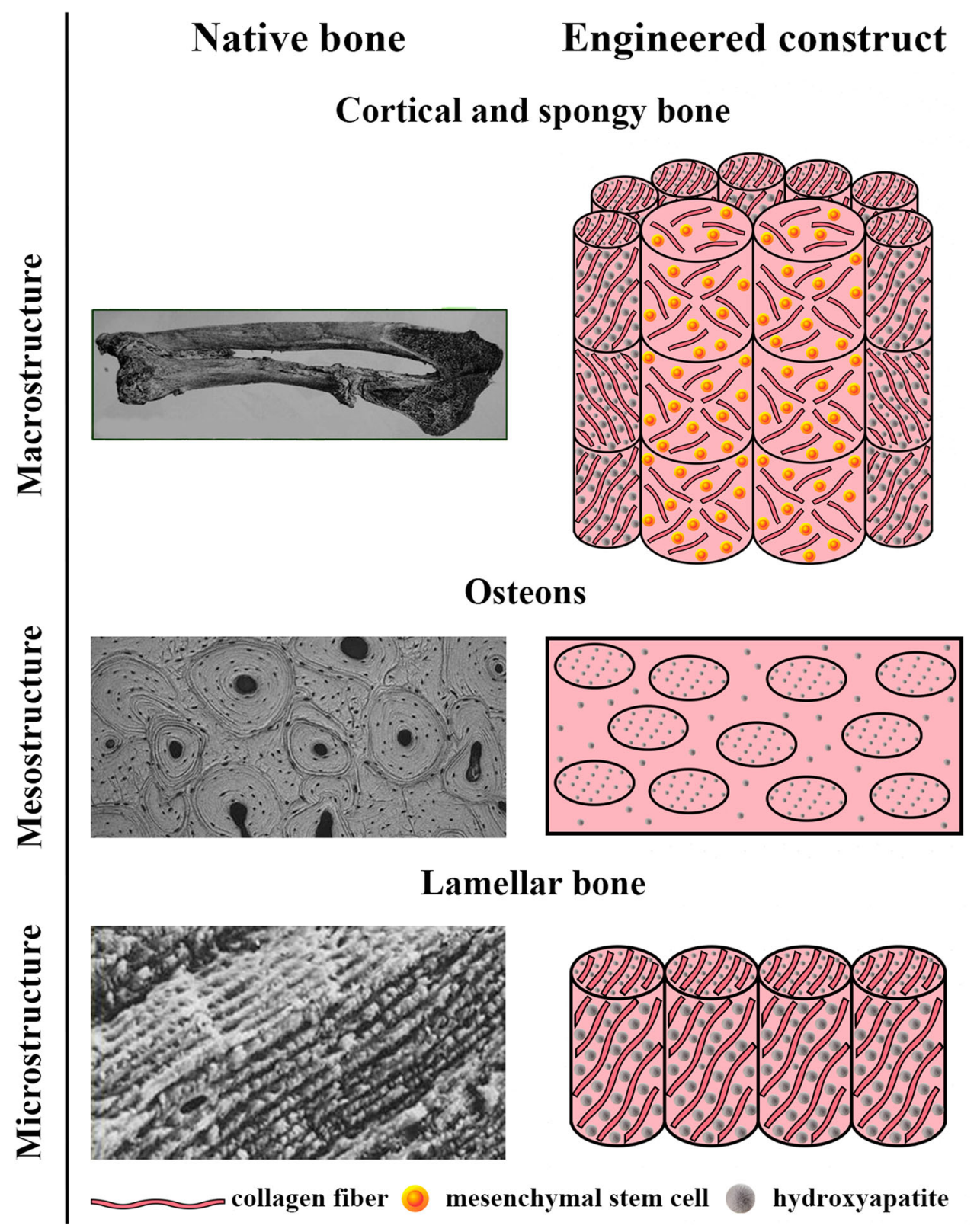

Figure 6. Examples of possible engineered structures inspired by the hierarchical levels of native bone. Lamellar bone could be mimicked by combining mineralised collagen bioinks with a predefined fibrillar directionality produced through GAE. Osteons could be replicated by embedding mineralised collagen bioinks of desired structures in a collagenous solution, which could be subsequently densified through different approaches (e.g. evaporation or plastic compression). Cortical and spongy bone could be modelled by surrounding loose collagen bioinks with denser and anisotropic bioinks. In particular, the bioinks constituting the core could be seeded with mesenchymal stem cells while the outer layer could be built up by mineralised collagen bioinks characterised by different patterns of fibrillar alignment. Images of native cortical and spongy bone, osteons and lamellar bone are adapted from [44].

approaches. Depending on the target tissue, the most appropriate pre- or post-fibrillogenesis approach can be applied to better mimic the native architecture, followed by its mineralisation. In this context, the main limitation of these techniques, namely the size of the scaffold, which is in the order of millimetres, may be overcome by their use as fillers to promote tissue regeneration. In particular, when a defect is characterised by a critical size, it does not heal and the use of a scaffolding material incorporated with a bioactive agent to stimulate host cell activity, may represent an interesting approach to accelerate its regeneration. The mid- term objective should focus on overcoming the limitation of the scaffold size as well as exploring the possibility of building complex structures. The combination of constructs produced via different pre- or post-fibrillogenesis approaches, characterised by well-defined architectures, may represent a great deal of interest to build-up scaffolds with multiple hierarchical levels of organisation. Once it will be possible to reproduce multiple hierarchical levels of bone organisation, the longterm objective could focus on the incorporation of osteoblastic cells in an attempt to fully regenerate the tissue. 


\section{Conclusions}

Collagen has long been applied as a biomaterial in the design of a scaffold attributable to its biocompatibility and biodegradability. However, highly hydrated collagen hydrogels lack the structural and mechanical properties to be applied in bone tissue engineering. In order to better mimic the organic milieu of bone and realise functional osteoid-like dense collagen scaffolds with potential applications in bone regenerative therapy, several pre- and post-fibrillogenesis approaches have been developed to increase the collagen concentration/density of the construct. By defining their micro-architectures, creating different levels of fibrillar orientations and tailoring their mechanical properties, these approaches increase the tissueequivalency of these constructs. These features also regulate the osteoblastic differentiation of seeded mesenchymal stem cells and can therefore be potentially used for cell delivery as an osteogenic bone graft substitute. However, while cell delivery is an attractive approach, it is recognised that the regulatory path to clinical application of cell therapy is long. Nevertheless, recent in vivo studies have suggested that acellular injectable dense collagen gels fabricated through gel aspiration-ejection and hybridised with orthobiologics, demonstrate potential in mineralised tissue repair as osteoinductive bone graft substitutes. Furthermore, this technology has recently been demonstrated to provide the basis for the bioprinting of dense collagen-based bioinks. Automated gel aspiration-ejection provides the high-throughput biofabricatation of constructs with tailored structural, biological and mechanical properties, thereby possibly providing organ-like structures, which will drastically reduce the number of animals in pre-clinical testing. It also offer promise in reducing the complexity of surgical procedures and accelerating post-operative healing by rapidly replicating customised, multifaceted designs. Therefore, it can be postulated that printable dense collagen bioinks may lead to implantable materials that demonstrate more rapid and greater levels of host integration for bone repair and regeneration.

\section{Acknowledgements}

Funding from NSERC, CIHR, FRQNT, CFI, and McGill Faculty of Engineering, as well as the contributions of the graduate students from the Nazhat lab at McGill University are gratefully acknowledged. This review is dedicated to the late Professor Robert A Brown (1952-2016) who was a pioneer in the development of cell-independent engineering of tissues through plastic compression and RAFT ${ }^{\mathrm{TM}}$.

\section{Disclosure statement}

Showan N. Nazhat is a named inventor on PCT/GB2005/ 002631 entitled 'Cell-independent fabrication of tissue equivalents'. A product has been developed based on the invention: RAFTTM 3D Cell Culture System. He is also a named inventor on PCT/CA2013/050615 entitled 'Dense hydrogels'.

\section{ORCID}

Gabriele Griffanti (D) http://orcid.org/0000-0002-6904-9211 Showan N. Nazhat (D) http://orcid.org/0000-0002-8134-183X

\section{References}

[1] Henkel J, Woodruff MA, Epari DR, et al. Bone regeneration based on tissue engineering conceptions - a 21st century perspective. Bone Res. 2013;1 (3):216-248.

[2] Hutmacher DW. Scaffolds in tissue engineering bone and cartilage. Biomaterials. 2000;21(24):2529-2543.

[3] Nelson CM, Bissell MJ. Of extracellular matrix, scaffolds, and signaling: tissue architecture regulates development, homeostasis, and cancer. Annu Rev Cell Dev Biol. 2006;22:287-309.

[4] Gattazzo F, Urciuolo A, Bonaldo P. Extracellular matrix: a dynamic microenvironment for stem cell niche. Biochim Biophy Acta, Gen Subj. 2014;1840 (8):2506-2519.

[5] Kawasaki K, Buchanan AV, Weiss KM. Biomineralization in humans: making the hard choices in life. Annu Rev Genet. 2009;43:119-142.

[6] Reznikov N, Bilton M, Lari L, et al. Fractal-like hierarchical organization of bone begins at the nanoscale. Science. 2018;360(6388):eaao2189.

[7] Cen L, Liu W, Cui L, et al. Collagen tissue engineering: development of novel biomaterials and applications. Pediatr Res. 2008;63(5):492-496.

[8] Ferreira AM, Gentile P, Chiono V, et al. Collagen for bone tissue regeneration. Acta Biomater. 2012;8 (9):3191-3200.

[9] Benders KEM, Weeren P, Badylak SF, et al. Extracellular matrix scaffolds for cartilage and bone regeneration. Trends Biotechnol. 2013;31 (3):169-176.

[10] Brodsky B, Ramshaw JAM. The collagen triple-helix structure. Matrix Biol. 1997;15(8-9):545-554.

[11] Trelstad RL, Hayashi K. Tendon collagen fibrillogenesis: intracellular subassemblies and cell surface changes associated with fibril growth. Dev Biol. 1979;71(2):228-242.

[12] Silver FH, Langley KH, Trelstad RL. Type I collagen fibrillogenesis: initiation via reversible linear and lateral growth steps. Biopolymers. 1979;18 (10):2523-2535.

[13] Pedersen JA, Boschetti F, Swartz MA. Effects of extracellular fiber architecture on cell membrane shear stress in a 3D fibrous matrix. J Biomech. 2007;40 (7):1484-1492.

[14] Brown RA, Wiseman M, Chuo CB, et al. Ultrarapid engineering of biomimetic materials and tissues: fabrication of nano- and microstructures by plastic compression. Adv Funct Mater. 2005;15(11):1762-1770.

[15] Brinkman WT, Nagapudi K, Thomas BS, et al. Photocross-linking of type I collagen gels in the presence of smooth muscle cells: mechanical properties, cell viability, and function. Biomacromolecules. 2003;4 (4):890-895.

[16] Giraud-Guille MM. Liquid crystalline phases of sonicated type I collagen. Biol Cell. 1989;67(1):97-101. 
[17] Giraud-Guille MM, Besseau L. Banded patterns in liquid crystalline phases of type I collagen: relationship with crimp morphology in connective tissue architecture. Connect Tissue Res. 1998;37(34):183-193.

[18] Nassif N, Gobeaux F, Seto J, et al. Self-assembled collagen-apatite matrix with bone-like hierarchy. Chem Mater. 2010;22(11):3307-3309.

[19] Nassif N, Martineau F, Syzgantseva O, et al. In vivo inspired conditions to synthesize biomimetic hydroxyapatite. Chem Mater. 2010;22(12):3653-3663.

[20] Wang Y, Von Euw S, Fernandes FM, et al. Watermediated structuring of bone apatite. Nat Mater. 2013;12(12):1144-1153.

[21] Silvent J, Nassif N, Helary C, et al. Collagen osteoidlike model allows Kinetic Gene expression studies of Non-collagenous proteins in Relation with mineral development to Understand bone biomineralization. Plos One. 2013;8(2):e57344.

[22] Vigier S, Helary C, Fromigue O, et al. Collagen supramolecular and suprafibrillar organizations on osteoblasts long-term behavior: benefits for bone healing materials. J Biomed Mater Res Part A. 2010;94 (2):556-567.

[23] Marelli B, Ghezzi CE, James-Bhasin $M$, et al. Fabrication of injectable, cellular, anisotropic collagen tissue equivalents with modular fibrillar densities. Biomaterials. 2015;37:183-193.

[24] Zitnay JL, Reese SP, Tran G, et al. Fabrication of dense anisotropic collagen scaffolds using biaxial compression. Acta Biomater. 2018;65:76-87.

[25] Abou Neel EA, Cheema U, Knowles JC, et al. Use of multiple unconfined compression for control of collagen gel scaffold density and mechanical properties. Soft Matter. 2006;2(11):986-992.

[26] Marelli B, Ghezzi CE, Barralet JE, et al. Collagen gel fibrillar density dictates the extent of mineralization in vitro. Soft Matter. 2011;7(21):9898-9907.

[27] Bitar M, Salih V, Brown RA, et al. Effect of multiple unconfined compression on cellular dense collagen scaffolds for bone tissue engineering. J Mater Sci: Mater Med. 2007;18(2):237-244.

[28] Bitar M, Brown RA, Salih V, et al. Effect of cell density on osteoblastic differentiation and matrix degradation of biomimetic dense collagen scaffolds. Biomacromolecules. 2008;9(1):129-135.

[29] Serpooshan V, Julien M, Nguyen O, et al. Reduced hydraulic permeability of three-dimensional collagen scaffolds attenuates gel contraction and promotes the growth and differentiation of mesenchymal stem cells. Acta Biomater. 2010;6(10):3978-3987.

[30] Miri AK, Muja N, Kamranpour NO, et al. Ectopic bone formation in rapidly fabricated acellular injectable dense collagen-Bioglass hybrid scaffolds via gel aspiration-ejection. Biomaterials. 2016;85:128-141.

[31] Chamieh F, Collignon A-M, Coyac BR, et al. Accelerated craniofacial bone regeneration through dense collagen gel scaffolds seeded with dental pulp stem cells. Sci Rep. 2016;6:38814.

[32] Nimni ME, Cheung D, Strates B, et al. Chemically modified collagen: a natural biomaterial for tissue replacement. J Biomed Mater Res. 1987;21 (6):741-771.

[33] Merrett K, Ljunggren MK, Mondal D, et al. Collagen type I: a promising scaffold material for tissue engineering and regenerative medicine. In: Henriques ME, Pinto M, editors. Type I collagen: biological functions, synthesis and medicinal applications. Nova Science Publishers, Inc.; 2012. p. 1-43.

[34] Van der Rest M, Garrone R. Collagen family of proteins. FASEB J. 1991;5(13):2814-2823.

[35] Gelse K, Pöschl E, Aigner T. Collagens - Structure, function, and biosynthesis. Adv Drug Deliv Rev. 2003;55(12):1531-1546.

[36] Hulmes DJS, Miller A. Molecular packing in collagen. Nature. 1981;293(5829):239-240.

[37] Trammell LH, Kroman AM. Chapter 13 - bone and dental histology. In: DiGangi EA, Moore MK, editors. Research methods in human skeletal biology. Waltham, MA: Academic Press; 2013. p. 361-395.

[38] Olszta MJ, Cheng X, Jee SS, et al. Bone structure and formation: a new perspective. Mater Sci Eng R: Rep. 2007;58(3-5):77-116.

[39] Weiner S, Traub W. Organization of hydroxyapatite crystals within collagen fibrils. FEBS Lett. 1986;206 (2):262-266.

[40] Weiner S, Traub W, Wagner HD. Lamellar bone: structure-function relations. J Struct Biol. 1999;126 (3):241-255.

[41] Weiner S, Wagner HD. The material bone: structuremechanical function relations. Annu Rev Mater Sci. 1998;28(1):271-298.

[42] Landis WJ, Hodgens KJ, Song MJ, et al. Mineralization of collagen may occur on fibril surfaces: evidence from conventional and high-voltage electron microscopy and three-dimensional imaging. J Struct Biol. 1996;117(1):24-35.

[43] Kawasaki K, Buchanan AV, Weiss KM. Biomineralization in humans: making the hard choices in life. Annu Rev Genet. 2009;43(1):119-142.

[44] Reznikov N, Shahar R, Weiner S. Bone hierarchical structure in three dimensions. Acta Biomater. 2014;10(9):3815-3826.

[45] Jia M, Hong Y, Duan S, et al. The influence of transition metal ions on collagen mineralization. Mater Sci Eng C. 2013;33(4):2399-2406.

[46] Glimcher MJ. Mechanism of calcification: role of collagen fibrils and collagen-phosphoprotein complexes in vitro and in vivo. Anat Rec. 1989;224(2):139-153.

[47] Clarke B. Normal bone anatomy and physiology. Clin J Am Soc Nephrol: CJASN. 2008;3(Suppl 3): S131-S139.

[48] George A, Veis A. Phosphorylated proteins and control over apatite nucleation, crystal growth, and inhibition. Chem Rev. 2008;108(11):4670-4693.

[49] Niu LN, Jee SE, Jiao K, et al. Collagen intrafibrillar mineralization as a result of the balance between osmotic equilibrium and electroneutrality. Nat Mater. 2016;16:370-378.

[50] Kim HJ, Kim UJ, Kim HS, et al. Bone tissue engineering with premineralized silk scaffolds. Bone. 2008;42 (6):1226-1234.

[51] Gross J, Highberger JH, Schmitt FO. Some factors involved in the Fibrogenesis of collagen in vitro. Proc Soc Exp Biol Med. 1952;80(3):462-465.

[52] Jackson DS, Fessler JH. Isolation and properties of a collagen soluble in salt solution at neutral $\mathrm{pH}$. Nature. 1955;176(4471):69-70.

[53] Silver FH, Freeman JW, Seehra GP. Collagen selfassembly and the development of tendon mechanical properties. J Biomech. 2003;36(10):1529-1553.

[54] Bell E, Ehrlich HP, Sher S, et al. Development and use of a living skin equivalent. Plast Reconstr Surg. 1981;67(3):386-392. 
[55] Falanga V, Sabolinski M. A bilayered living skin construct $\left(\right.$ APLIGRAF ${ }^{\infty}$ ) accelerates complete closure of hard-to-heal venous ulcers. Wound Repair Regen. 1999;7(4):201-207.

[56] Tomasek JJ, Gabbiani G, Hinz B, et al. Myofibroblasts and mechano-regulation of connective tissue remodelling. Nat Rev Mol Cell Biol. 2002;3(5):349-363.

[57] Desmouliere A, Redard M, Darby I, et al. Apoptosis mediates the decrease in cellularity during the transition between granulation tissue and scar. Am J Pathol. 1995;146(1):56-66.

[58] Estes JM, Berg JSV, Adzick NS, et al. Phenotypic and functional features of myofibroblasts in sheep fetal wounds. Differentiation. 1994;56(3):173-181.

[59] Steinberg BM, Smith K, Colozzo M, et al. Establishment and transformation diminish the ability of fibroblasts to contract a native collagen gel. J Cell Biol. 1980;87(1):304-308.

[60] Grinnell F. Fibroblast-collagen-matrix contraction: growth-factor signalling and mechanical loading. Trends Cell Biol. 2000;10(9):362-365.

[61] Clark RA, Nielsen LD, Welch MP, et al. Collagen matrices attenuate the collagen-synthetic response of cultured fibroblasts to TGF-beta. J Cell Sci. 1995;108(3):1251-1261.

[62] Arora PD, Narani N, McCulloch CAG. The compliance of collagen gels regulates transforming growth factor- $\beta$ induction of $\alpha$-smooth muscle actin in fibroblasts. Am J Pathol. 1999;154(3):871-882.

[63] Fringer J, Grinnell F. Fibroblast quiescence in floating or released collagen matrices: contribution of the ERK signaling pathway and actin cytoskeletal organization. J Biol Chem. 2001;276(33):31047-31052.

[64] Weadock KS, Miller EJ, Bellincampi LD, et al. Physical crosslinking of collagen fibers: comparison of ultraviolet irradiation and dehydrothermal treatment. J Biomed Mater Res. 1995;29(11):1373-1379.

[65] Saito M, Marumo K. Collagen cross-links as a determinant of bone quality: a possible explanation for bone fragility in aging, osteoporosis, and diabetes mellitus. Osteoporos Int. 2010;21(2):195-214.

[66] Pfeffer CP, Olsen BR, Légaré F. Second harmonic generation imaging of fascia within thick tissue block. Opt Express. 2007;15(12):7296-7302.

[67] Kew SJ, Gwynne JH, Enea D, et al. Regeneration and repair of tendon and ligament tissue using collagen fibre biomaterials. Acta Biomater. 2011;7 (9):3237-3247.

[68] Cornwell KG, Lei P, Andreadis ST, et al. Crosslinking of discrete self-assembled collagen threads: effects on mechanical strength and cell-matrix interactions. J Biomed Mater Res Part A. 2007;80(2):362-371.

[69] Nishi C, Nakajima N, Ikada Y. In vitro evaluation of cytotoxicity of diepoxy compounds used for biomaterial modification. J Biomed Mater Res. 1995;29 (7):829-834.

[70] Speer DP, Chvapil M, Eskelson CD, et al. Biological effects of residual glutaraldehyde in glutaraldehydetanned collagen biomaterials. J Biomed Mater Res. 1980;14(6):753-764.

[71] Knight DP, Nash L, Hu XW, et al. In vitro formation by reverse dialysis of collagen gels containing highly oriented arrays of fibrils. J Biomed Mater Res. 1998;41(2):185-191.

[72] Besseau L, Coulomb B, Lebreton-Decoster C, et al. Production of ordered collagen matrices for three- dimensional cell culture. Biomaterials. 2002;23 (1):27-36.

[73] Mosser G, Anglo A, Helary C, et al. Dense tissue-like collagen matrices formed in cell-free conditions. Matrix Biol. 2006;25(1):3-13.

[74] Wang Y, Silvent J, Robin M, et al. Controlled collagen assembly to build dense tissue-like materials for tissue engineering. Soft Matter. 2011;7(20):9659-9664.

[75] Kamranpour NO, Miri AK, James-Bhasin M, et al. A gel aspiration-ejection system for the controlled production and delivery of injectable dense collagen scaffolds. Biofabrication. 2016;8(1):015018.

[76] Griffanti G, Rezabeigi E, Li J, et al. Rapid biofabrication of printable dense collagen bioinks of tunable properties. Adv Funct Mater. 2020;30:1903874.

[77] Besseau L, Giraud-Guille MM. Stabilization of fluid cholesteric phases of collagen to ordered gelated matrices. J Mol Biol. 1995;251(2):197-202.

[78] Zhou J, Xu C, Wu G, et al. In vitro generation of osteochondral differentiation of human marrow mesenchymal stem cells in novel collagen-hydroxyapatite layered scaffolds [article]. Acta Biomater. 2011;7(11):3999-4006.

[79] Giraud-Guille MM, Mosser G, Belamie E. Liquid crystallinity in collagen systems in vitro and in vivo. Curr Opin Colloid Interface Sci. 2008;13(4):303-313.

[80] Ramtani S, Takahashi-IÑiguez Y, Helary C, et al. Mechanical behavior under unconfined compression loadings of dense fibrillar collagen matrices mimetic of living tissues. J Mech Med Biol. 2010;10(1):35-55.

[81] Helary C, Foucault-Bertaud A, Godeau G, et al. Fibroblast populated dense collagen matrices: cell migration, cell density and metalloproteinases expression. Biomaterials. 2005;26(13):1533-1543.

[82] Serpooshan V, Muja N, Marelli B, et al. Fibroblast contractility and growth in plastic compressed collagen gel scaffolds with microstructures correlated with hydraulic permeability. J Biomed Mater Res Part A. 2011;96 A(4):609-620.

[83] O’Rourke C, Day AGE, Murray-Dunning C, et al. An allogeneic 'off the shelf therapeutic strategy for peripheral nerve tissue engineering using clinical grade human neural stem cells. Sci Rep. 2018;8(1):2951.

[84] Ghezzi CE, Marelli B, Donelli I, et al. Multilayered dense collagen-silk fibroin hybrid: a platform for mesenchymal stem cell differentiation towards chondrogenic and osteogenic lineages. J Tissue Eng Regen Med. 2017;11(7):2046-2059.

[85] Engelhardt EM, Stegberg E, Brown RA, et al. Compressed collagen gel: a novel scaffold for human bladder cells. J Tissue Eng Regen Med. 2010;4(2):123-130.

[86] East E, De Oliveira DB, Golding JP, et al. Alignment of astrocytes increases neuronal growth in threedimensional collagen gels and is maintained following plastic compression to form a spinal cord repair conduit. Tissue Eng Part A. 2010;16(10):3173-3184.

[87] Levis HJ, Brown RA, Daniels JT. Plastic compressed collagen as a biomimetic substrate for human limbal epithelial cell culture. Biomaterials. 2010;31 (30):7726-7737.

[88] Pedraza CE, Marelli B, Chicatun F, et al. An in vitro assessment of a cell-containing collagenous extracellular matrix-like scaffold for bone tissue engineering. Tissue Eng Part A. 2010;16(3):781-793. Mary Ann Liebert, Inc. 
[89] Ghezzi CE, Marelli B, Muja N, et al. Mesenchymal stem cell-seeded multilayered dense collagen-silk fibroin hybrid for tissue engineering applications. Biotechnol J. 2011;6(10):1198-1207.

[90] Ghezzi CE, Marelli B, Muja N, et al. Immediate production of a tubular dense collagen construct with bioinspired mechanical properties. Acta Biomater. 2012;8(5):1813-1825.

[91] Chicatun F, Rezabeigi E, Muja N, et al. A bilayered dense collagen/chitosan hydrogel to model the osteochondral interface. Emergent Mater. 2019 2019/06/ 01;2(2):245-262.

[92] Nazhat SN, Abou Neel EA, Kidane A, et al. Controlled microchannelling in dense collagen scaffolds by soluble phosphate glass fibers. Biomacromolecules. 2007;8(2):543-551.

[93] Marelli B, Ghezzi CE, Alessandrino A, et al. Silk fibroin derived polypeptide-induced biomineralization of collagen. Biomaterials. 2012 1//;33 (1):102-108.

[94] Marelli B, Ghezzi CE, Barralet JE, et al. Three-dimensional mineralization of dense nanofibrillar collagenbioglass hybrid scaffolds. Biomacromolecules. 2010;11(6):1470-1479.

[95] Cheema U, Rong Z, Kirresh O, et al. Oxygen diffusion through collagen scaffolds at defined densities: implications for cell survival in tissue models. J Tissue Eng Regen Med. 2012;6(1):77-84.

[96] Cheng G, Youssef BB, Markenscoff P, et al. Cell population dynamics modulate the rates of tissue growth processes. Biophys J. 2006;90(3):713-724.

[97] Hadjipanayi E, Mudera V, Brown RA. Close dependence of fibroblast proliferation on collagen scaffold matrix stiffness. J Tissue Eng Regen Med. 2009;3 (2):77-84.

[98] $\mathrm{Hu} \mathrm{K}$, Shi H, Zhu J, et al. Compressed collagen gel as the scaffold for skin engineering. Biomed Microdevices. 2010;12(4):627-635.

[99] Braziulis E, Diezi M, Biedermann T, et al. Modified plastic compression of collagen hydrogels provides an ideal matrix for clinically applicable skin substitutes. Tissue Eng Part C: Methods. 2012;18 (6):464-474.

[100] Martin YH, Jubin K, Smalley S, et al. A novel system for expansion and delivery of human keratinocytes for the treatment of severe cutaneous injuries using microcarriers and compressed collagen. J Tissue Eng Regen Med. 2017;11:3124-3133.

[101] Georgiou M, East E, Loughlin J, et al. Schwann cells in collagen gels survive plastic compression and maintain their alignment: development of a cellular biomaterial for peripheral nerve repair. Eur Cells Mater. 2011;22(SUPPL.2):49.

[102] Coyac BR, Chicatun F, Hoac B, et al. Mineralization of dense collagen hydrogel scaffolds by human pulp cells. J Dent Res. 2013;92(7):648-654.

[103] Rosenzweig DH, Chicatun F, Nazhat SN, et al. Cartilaginous constructs using primary chondrocytes from continuous expansion culture seeded in dense collagen gels. Acta Biomater. 2013;9(12):9360-9369.

[104] Mudera V, Morgan M, Cheema U, et al. Ultra-rapid engineered collagen constructs tested in an in vivo nursery site. J Tissue Eng Regen Med. 2007;1 (3):192-198.

[105] Ghezzi CE, Risse PA, Marelli B, et al. An airway smooth muscle cell niche under physiological pulsatile flow culture using a tubular dense collagen construct. Biomaterials. 2013;34(8):1954-1966.

[106] Micol LA, Ananta M, Engelhardt E-M, et al. Highdensity collagen gel tubes as a matrix for primary human bladder smooth muscle cells. Biomaterials. 2011 2//;32(6):1543-1548.

[107] Mi S, Chen B, Wright B, et al. Plastic compression of a collagen gel forms a much improved scaffold for ocular surface tissue engineering over conventional collagen gels. J Biomed Mater Res Part A. 2010;95 A (2):447-453.

[108] Levis HJ, Menzel-Severing J, Drake RAL, et al. Plastic compressed collagen constructs for ocular cell culture and transplantation: a new and improved technique of confined fluid loss. Curr Eye Res. 2013;38(1):41-52.

[109] Brady MA, Sivananthan S, Mudera V, et al. The primordium of a biological joint replacement: coupling of two stem cell pathways in biphasic ultrarapid compressed gel niches. J Cranio-Maxillofacial Surg. 2011;39(5):380-386.

[110] Serpooshan V, Zhao M, Metzler SA, et al. The effect of bioengineered acellular collagen patch on cardiac remodeling and ventricular function post myocardial infarction. Biomaterials. 2013;34(36):9048-9055.

[111] Raison C, Porter S, Fedele S, et al. Collagen gel as a 3D in vitro tissue model for ameloblastoma studies. Eur Cells Mater. 2011;22(SUPPL.2):86.

[112] Nyga A, Loizidou M, Emberton M, et al. A novel tissue engineered three-dimensional in vitro colorectal cancer model. Acta Biomater. 2013;9(8):7917-7926.

[113] James-Bhasin M, Siegel MP, Nazhat NS. A threedimensional dense collagen hydrogel to model cancer cell/osteoblast interactions. J Funct Biomater. 2018;9 (4):72.

[114] Guille MM G, Helary C, Vigier S, et al. Dense fibrillar collagen matrices for tissue repair. Soft Matter. 2010;6 (20):4963-4967.

[115] Sadat-Shojai M, Khorasani M-T, DinpanahKhoshdargi E, et al. Synthesis methods for nanosized hydroxyapatite with diverse structures. Acta Biomater. 2013;9(8):7591-7621.

[116] Amini AR, Laurencin CT, Nukavarapu SP. Bone tissue engineering: recent advances and challenges. Crit Rev Biomed Eng. 2012;40(5):363-408.

[117] Karageorgiou V, Kaplan D. Porosity of 3D biomaterial scaffolds and osteogenesis. Biomaterials. 2005;26 (27):5474-5491.

[118] Reznikov N, Steele JAM, Fratzl P, et al. A materials science vision of extracellular matrix mineralization. Nat Rev Mater. 2016;1(16041).

[119] Amos FF, Olszta MJ, Khan SR, et al. Relevance of a polymer-induced liquid-precursor (PILP) mineralization process to normal and pathological biomineralization. biomineralization - medical aspects of solubility. Hoboken (NJ): Wiley Blackwell; 2006. p. 125-217.

[120] Wang Y, Azaïs T, Robin M, et al. The predominant role of collagen in the nucleation, growth, structure and orientation of bone apatite. Nat Mater. 2012;11 (8):724-733.

[121] Wingender B, Bradley P, Saxena N, et al. Biomimetic organization of collagen matrices to template bonelike microstructures. Matrix Biol. 2016;5254:384-396.

[122] Marelli B, Ghezzi CE, Zhang YL, et al. Fibril formation $\mathrm{pH}$ controls intrafibrillar collagen 
biomineralization invitro and invivo. Biomaterials. 2015;37:252-259.

[123] Marelli B, Ghezzi CE, Mohn D, et al. Accelerated mineralization of dense collagen-nano bioactive glass hybrid gels increases scaffold stiffness and regulates osteoblastic function. Biomaterials. 2011;32 (34):8915-8926.

[124] Griffanti G, Jiang W, Nazhat SN. Bioinspired mineralization of a functionalized injectable dense collagen hydrogel through silk sericin incorporation. Biomater Sci. 2018;7:1064-1077.

[125] Nudelman F, Pieterse K, George A, et al. The role of collagen in bone apatite formation in the presence of hydroxyapatite nucleation inhibitors. Nat Mater. 2010;9(12):1004-1009.

[126] Misra SK, Mohn D, Brunner TJ, et al. Comparison of nanoscale and microscale bioactive glass on the properties of $\mathrm{P}(3 \mathrm{HB}) /$ bioglass $^{\oplus}$ composites. Biomaterials. 2008;29(12):1750-1761.

[127] Kim D, Lee B, Thomopoulos S, et al. The role of confined collagen geometry in decreasing nucleation energy barriers to intrafibrillar mineralization. Nat Commun. 2018;9(1):962.

[128] Palmer LC, Newcomb CJ, Kaltz SR, et al. Biomimetic systems for hydroxyapatite mineralization inspired by bone and enamel. Chem Rev. 2008;108(11):47544783.

[129] Jee SS, Culver L, Li Y, et al. Biomimetic mineralization of collagen via an enzyme-aided PILP process. J Cryst Growth. 2010;312(8):1249-1256.

[130] Hartgerink JD, Beniash E, Stupp SI. Self-assembly and mineralization of peptide-amphiphile nanofibers. Science. 2001;294(5547):1684-1688.

[131] Góes JC, Figueiró SD, Oliveira AM, et al. Apatite coating on anionic and native collagen films by an alternate soaking process. Acta Biomater. 2007;3(5):773778.

[132] Helary C, Ovtracht L, Coulomb B, et al. Dense fibrillar collagen matrices: a model to study myofibroblast behaviour during wound healing. Biomaterials. 2006;27(25):4443-4452.

[133] Vigier S, Catania C, Baroukh B, et al. Dense fibrillar collagen matrices sustain osteoblast phenotype in vitro and promote bone formation in rat calvaria defect. Tissue Eng Part A. 2011;17(7-8):889-898. Mary Ann Liebert, Inc.

[134] Engler AJ, Sen S, Sweeney HL, et al. Matrix elasticity directs stem cell lineage specification. Cell. 2006 2006/ 08/25/;126(4):677-689.

[135] Buxton PG, Bitar M, Gellynck K, et al. Dense collagen matrix accelerates osteogenic differentiation and rescues the apoptotic response to MMP inhibition. Bone. 2008;43(2):377-385.

[136] Chicatun F, Muja N, Serpooshan V, et al. Effect of chitosan incorporation on the consolidation process of highly hydrated collagen hydrogel scaffolds
[10.1039/C3SM52176A]. Soft Matter. 2013;9 (45):10811-10821.

[137] Marelli B, Ghezzi CE, Alessandrino A, et al. Anionic fibroin-derived polypeptides accelerate MSC osteoblastic differentiation in a three-dimensional osteoid-like dense collagen niche. J Mater Chem B. 2014;2(33):5339-5343.

[138] Chicatun F, Pedraza CE, Muja N, et al. Effect of chitosan incorporation and scaffold geometry on chondrocyte function in dense collagen type i hydrogels. Tissue Eng Part A. 2013;19(23-24):2553-2564.

[139] Chicatun F, Pedraza CE, Ghezzi CE, et al. OsteoidMimicking dense collagen/chitosan Hybrid gels. Biomacromolecules. 2011;12(8):2946-2956.

[140] Anderson HC. Molecular biology of matrix vesicles. Clin Orthop Relat Res. 1995;314:266-280.

[141] Boskey AL. Matrix proteins and mineralization: an overview. Connect Tissue Res. 1996;35(1-4):357-363.

[142] Badylak SF. The extracellular matrix as a scaffold for tissue reconstruction. Semin Cell Dev Biol. 2002;13 (5):377-383.

[143] Xynos ID, Edgar AJ, Buttery LDK, et al. Ionic products of bioactive glass dissolution increase proliferation of human osteoblasts and induce insulin-like growth factor II mRNA expression and protein synthesis. Biochem Biophys Res Commun. 2000;276 (2):461-465.

[144] Hattar S, Asselin A, Greenspan D, et al. Potential of biomimetic surfaces to promote in vitro osteoblastlike cell differentiation. Biomaterials. 2005;26 (8):839-848.

[145] Bosetti M, Cannas M. The effect of bioactive glasses on bone marrow stromal cells differentiation. Biomaterials. 2005;26(18):3873-3879.

[146] Xynos ID, Edgar AJ, Buttery LDK, et al. Gene-expression profiling of human osteoblasts following treatment with the ionic products of Bioglass ${ }^{\oplus}$ S55 dissolution. J Biomed Mater Res. 2001;55(2):151-157.

[147] Leu A, Leach JK. Proangiogenic potential of a collagen/bioactive glass substrate. Pharm Res. 2008;25 (5):1222-1229.

[148] Kneser U, Schaefer DJ, Polykandriotis E, et al. Tissue engineering of bone: the reconstructive surgeon's point of view. J Cell Mol Med. 2006;10(1):7-19.

[149] Cancedda R, Giannoni P, Mastrogiacomo M. A tissue engineering approach to bone repair in large animal models and in clinical practice. Biomaterials. 2007;28(29):4240-4250.

[150] Fröhlich M, Grayson WL, Wan LQ, et al. Tissue engineered bone grafts: biological requirements, tissue culture and clinical relevance. Current Stem Cell Res Ther. 2008;3(4):254-264.

[151] Carrier RL, Rupnick M, Langer R, et al. Effects of oxygen on engineered cardiac muscle. Biotechnol Bioeng. 2002;78(6):617-625. 